\title{
Younger Federal District Court Judges Favor Presidential Power
}

\author{
by
}

\section{Tom Campbell and Nathaniel T. Wilcox ${ }^{*}$}

\begin{abstract}
From 1960 to 2015, opinions of U.S. Federal District Court judges (trial judges) in cases involving challenges to Executive Branch authority show that these judges favor Executive authority less as they age, with a sharp decline beginning near age 57 . We argue that District judges know that elevation to the Federal Circuit Court of Appeals becomes increasingly improbable, and hence have less reason to 'cooperate' with the Executive, with advancing age. Political variables, seniority of judges, and other variables introduced as extra regressors do not reverse this main result, nor does it appear to be the product of cohort effects or selection off the District Court. When there are contemporaneous vacancies on their Circuit courts, District judges in the eleven State Circuits (but not the District of Columbia circuit) are also more likely to favor the Executive.
\end{abstract}

September 21st, 2018

Keywords: Elevation of Judges, Judicial Behavior, Life-cycle Behavior

JEL Codes: K40

${ }^{*}$ Campbell-Professor of Law, Fowler School of Law, Chapman University; Professor of Economics, Argyros School of Business and Economics, Chapman University, tcampbell@chapman.edu; WilcoxProfessor of Economics, Economics Science Institute, Argyros School of Business and Economics, Chapman University, nwilcox@chapman.edu. We are in deep debt to research librarians Isa Lang, J.D., M.L.S., and Sherry Leysen, J.D., M.L.S., of the Fowler School of Law, Chapman University, for indispensable help assembling our data sets. We thank Robert Carp and Jeff Smith for helpful comments. We are solely responsible for remaining errors. 


\section{Introduction}

In searching for a replacement for William O. Douglas, himself appointed to the Supreme Court at age 40, President Gerald Ford explicitly stated a preference for a nominee no older than $55 .{ }^{1}$ Of 114 Associate and Chief Justices of the US Supreme Court, half were 55 or younger (and just 14 were over age 60) at their appointment. ${ }^{2}$ It is logical that Presidents would want their judicial appointments to last.

Though elevation to the Supreme Court may be beyond wishing, a Federal District Court judge (or "District judge") may realistically hope for elevation to a Federal Circuit Court of Appeals. Epstein, Landes and Posner (2013, p. 337) note that "10 percent of district judges have been promoted to a Court of Appeals or the Supreme Court since 1933," ${ }^{3}$ and Kozinski (2004, p. 1104) remarks that "Every magistrate judge is a district judge in waiting; every district judge is a circuit judge in waiting; every circuit judge is an associate justice in waiting; and every associate justice is a chief justice in waiting."

Practical District judges will, however, know the implications of Executive preference for longlasting appointments: Advancing age diminishes the likelihood of their elevation. ${ }^{4}$ Figure 1 illustrates this reality. The gray graph shows, at each age $A$ of District judges, the remaining lifetime proportion of those District judges who were elevated to the Circuit: We denote this function $H(A)$ and call it the agespecific cumulative future hazard for elevation (to the Circuit courts) or for brevity the "hazard for elevation." The black-and-white bar graph shows the cumulative distribution of ages at which these judges were first appointed to a District Court. Appointed at an unusually early age such as 40, a District judge had (at age 40) an appreciable one in five cumulative future hazard for elevation. But the median District judge was appointed at 50 years of age and, at appointment, had about a one in ten hazard for elevation. By age 63, a District judge's hazard for elevation had dropped just below one in fifty.

It is also logical that a President would consider a District judge's record on Executive authority before nominating said judge for the Circuit. Other things equal, Presidents (and their Attorneys

\footnotetext{
1 "When Ford Nominated John Paul Stevens," TIME magazine, December 8, 1975. Justice Stevens was 55 upon his nomination.

${ }^{2}$ The list includes 17 Chief Justices, of whom three were directly elevated from Associate Justice. For those three, Edward White (48), Harlan F. Stone (52), and William Rehnquist (47) their age at initial appointment was used. Two (John Rutledge and Charles Evans Hughes) were appointed to Chief Justice after a discontinuity from their service as Associate Justice, so their age at each appointment was used in this tabulation. See Rotunda (2015, pp. xlix-lii). ${ }^{3}$ The probability of elevation of District judges hit its zenith around 1900, at just under 20\% (Klerman 1999). From 1918 to 2015 , we calculate the probability to be $9.61 \%$ (see the Figure 1 notes).

4 "The lesson for judges seeking promotion to the Supreme Court is clear: the likelihood of such a promotion will drop in the late 50 s and to near zero after 60 . The lesson for district judges... is similar, though not quite so extreme; although appointment to a court of appeals of someone 60 or older is rare, it is less rare than in the case of appointments to the Supreme Court" (Epstein, Landes and Posner 2013, p. 346).
} 
Figure 1: Age at which District Judges are First Appointed to the District Court; and Hazard for Elevation (at Each Age) to the Court of Appeals.
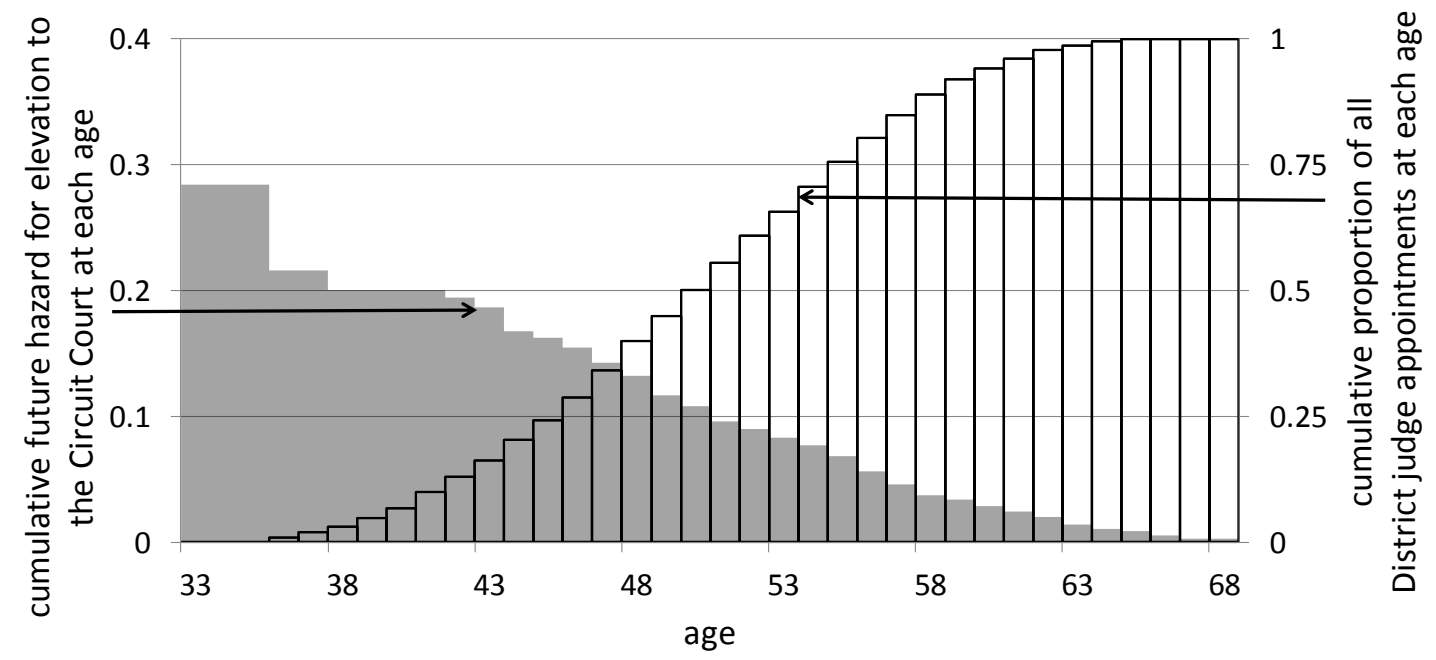

Source: Authors' calculations based on the "Biographical Directory of Federal Judges, 1789-present," Federal Judicial Center, www.fjc.gov/history/nome.nsf/page/judges.html, using all individuals who were confirmed as District judges on or after January 1st, 1918, but not after December 31st, 2015. This is a total of 2,446 District judges, of which 235 (or 9.61\%) were elevated to the Circuit Court of Appeals at some date between January 1st, 1918 and December 31st, 2015.

General) would want to see Circuit Courts populated with judges inclined to uphold Executive authority when challenged by Congress or by an individual, and such considerations could well trump party or ideology. For instance, though appointed to the District Court by Democratic President Jimmy Carter, Judge Harold Greene could hardly have expected a subsequent Democratic President, Bill Clinton, to forgive his ruling that Members of Congress had standing to challenge Republican President George H.W. Bush's war to expel Saddam Hussein from Kuwait. ${ }^{5}$ President Clinton would have had to worry how Judge Greene might rule if ever (as eventually did happen) ${ }^{6}$ President Clinton put US troops into war without Congressional approval.

We doubt that Judge Greene considered his possible elevation to the D.C. Circuit when ruling for Congress and against the President on war powers. He was 67 at the time of his ruling and would have

\footnotetext{
${ }^{5}$ Dellums v. Bush, 752 F. Supp. 1141 (D.D.C.1990).

${ }^{6}$ President Clinton bombed Yugoslavia for 79 days without Congressional approval (Halterman et al. 2001; Campbell 2004, p. 199 and p. 211 fn. 3).
} 
known he was realistically beyond consideration for elevation to the higher court. Moreover we suspect that some judges-perhaps including Judge Greene-would never allow that to enter their deliberations since it is extraneous to the merits of the case. Yet if an appreciable fraction of District judges do consider how their rulings affect their prospects for elevation to the Circuit court, our reasoning above suggests this would primarily appear in the rulings of relatively young judges, for whom the hazard for elevation to the Circuit is relatively high; but since this hazard declines monotonically as District judges age, we expect a decline in this motive for supporting the Executive with advancing age.

Our primary finding is that younger District judges are indeed more likely to favor the Executive than older District judges. Of course, age may bring some other change in the legal thinking, partisan leanings or other relevant cognitions of District judges. However, we have a secondary finding that cannot be explained by these alternative explanations of our primary finding: It appears that when there are contemporaneous vacancies on their Circuit courts, District judges in the eleven State Circuits (but not the District of Columbia Circuit) are also more likely to favor the Executive. We believe the simplest explanation for the two findings is that many District judges, particularly the younger ones in the eleven State Circuits, do indeed consider their careers when they write opinions concerning the Executive.

The U.S. Constitution encourages an independent Judiciary by means of life tenure and guarantee against diminution of compensation, yet checks and balances this by Executive appointment of Article III judges (with advice and consent of the Senate). Perhaps without any such intent, an institutional structure resembling a tournament or contest (Rosen 1988) emerges, creating a potential for the Executive to motivate desired behavior of District judges by means of awarding a fixed number of prizes (elevations to the federal Circuit Courts of Appeal). In a corporate management context Gibbs (1995, p. 249) found that "[For] employees who are passed over for promotion... performance falls as... they are passed over for longer. This does not seem to be due to a change in their within-job incentive scheme, but rather from dwindling hopes of winning promotion." One may think of a District judge's support for the Executive as similar to job performance (from the President's viewpoint), and ask whether "dwindling hopes of winning promotion" are associated with declining performance as found by Gibbs.

\section{Previous Literature}

Surveying literature exploring whether judges' promotion possibilities correlated with the content of their decisions, Baum (2006, p. 82) concludes that “...findings provide some evidence of a link between promotion prospects and decisional behavior, but the evidence is limited and mixed... In light 
of the importance of promotion to some judges, its impact on judicial behavior merits further inquiry." Among the views Baum cites is that of Posner (1995, p. 111) who, at the time, doubted that a Circuit judge would alter an opinion in order to enhance chances for appointment to the U.S. Supreme Court because "The impact of a single judicial decision on the prospects for such a promotion is normally very slight... and... the impact is unpredictable - the decision may offend as many influential people as it delights." Indeed members of the U.S. Senate might be less likely to confirm the author of an opinion upholding Presidential prerogatives against them.

Several years after Baum (2006) wrote, however, Posner appears to have found more plausibility to the theory that promotion prospects weigh on Federal judges' opinions, at least in some cases. Epstein, Landes and Posner (2013, pp. 376-9) found that "auditioners" (District judges who were eventually elevated to the Circuit court) tended to be tougher in sentencing than non-auditioners:

"The table [of results] reveals that the judges we classify as non-auditioners consistently gave lower prison sentences than the ones we classify as auditioners, and the difference is statistically significant. This is evidence of auditioning behavior, though it is not definitive, because the judges whom we are calling non-auditioners are really just judges who did not get promoted to the court of appeals. They may have wanted to be promoted, in which event they were auditioners who simply have not been promoted - yet; unless they have aged out of consideration, they may still be auditioners. ... To summarize, this chapter presents evidence, though it is not conclusive, that some judges do change their behavior in order to increase their chances of promotion."

Cohen (1992) also found statistically significant partial correlations between a promotion potential index and the fines and jail terms District judges imposed in antitrust cases. Similarly, Cohen (1991) and Sisk, Heise and Morriss (1998) found statistically significant partial correlations between indices of promotion potential and the likelihood that District judges upheld the constitutionality of the U.S. Sentencing Commission ${ }^{7}$-in line with positions of both political parties (and both their candidates for President) in the 1988 election year. Yet these same three studies produce very mixed results for partial correlations between their dependent variables and the age (or seniority) of District judges. ${ }^{8}$

While tough sentencing may have a perpetual political appeal, we think it may not be as important to a President as whether a judge will uphold Executive authority. Similarly, the constitutionality of the Sentencing Commission does not bear directly on Presidential powers; and Morriss, Heise and Sisk (2005, p. 93) noted some Executive ambivalence on this matter: "The Reagan Administration... was

\footnotetext{
${ }^{7}$ Of the 201 cases in our own sample, 24 were on the constitutionality of the U.S. Sentencing Commission. Our multivariate analyses in section 5.2 below will include controls for these cases.

${ }^{8}$ Promotion potential indices in these three studies are not based on either age or seniority, so the mixed results here do not stem from collinearity issues. By contrast Epstein, Landes and Posner (2013) used factor analysis to combine age and other variables into a single factor interpreted as promotion potential for a District Judge.
} 
divided over the constitutionality of the Guidelines.... Upholding the guidelines [sic] might curry favor with an incoming-Dukakis administration but was unlikely to make or break a judge's relationship with the new administration." We believe a set of cases specifically addressing Executive power is a more convincing environment for testing whether age influences the behavior of Federal District judges.

Black and Owens (2016) examined a sample of 36 Supreme Court vacancies between 1946 and 2010, comparing the opinions written by Circuit judges during the period of those vacancies who were (68 judges) and were not on presidential shortlists for those vacancies. They found that opinions of the former "contender judges" (those on the shortlists) were more in line with presidents' preferences than opinions of noncontender Circuit judges. This suggests that, at the time of a vacancy, a contender works a bit harder to flatter presidential preferences than a noncontender does. But Black and Owens (p. 35) point out that "We do not argue that when selecting nominees, presidents look only to their behavior during these vacancy periods. Rather, presidents look back to the behavior of judges over their careers for defining characteristics [emphasis in original]." Black and Owens' finding is fully consistent with the hypothesis that many Circuit judges have worked to achieve contender status over their careers (whether or not they achieved that status at the time of any particular vacancy). We also stress the rarity of supreme court vacancies relative to Circuit Court vacancies and the larger number of District judges potentially contending for those seats: Largely, our contribution beyond Black and Owens' substantial study consists of our new evidence concerning the behavior of District judges.

We draw several lessons from these existing studies. First, we will need to include controls for promotion potential in our own multivariate analysis. Section 4.2 and Appendix C discuss one such measure-a constructed promotion probability due to any Circuit Court vacancies at the time of District judges' opinions. Additionally, in Section 5.3 where we examine the robustness of our age effects, we follow both Cohen $(1991,1992)$ and Sisk, Heise and Morriss (1998) and add a measure based on the age of the oldest active Circuit judge each District judge could most plausibly aspire to replace when that Circuit judge exits from active service: This is meant to measure expectations of future vacancies.

Second, Sisk, Heise and Morriss (1998) argue that both theory and past evidence suggest that District judge seniority (as opposed to age itself) is the best age-related independent variable for their analysis and argue that collinearity precludes inclusion of both age and seniority as independent variables in the same specification; and Cohen $(1991,1992)$ also notes the collinearity issue. Nevertheless, in Section 5.3 we also examine the robustness of our age effect to the inclusion of a seniority variable. Our own reason for expecting an age effect fundamentally differs from Sisk, Heise and Morriss' (pp. 1486-7) theoretical reason for expecting a seniority effect. Therefore we must try to 
distinguish effects of age and seniority. This proves possible because age and seniority are sufficiently independent of one another in our new sample of opinions.

3. The Dependent Variable and its Suitability

At our request, research librarians assembled a new ${ }^{9}$ data set of every Federal District Court opinion from 1960 to 2015 included in Westlaw's database where the word "President" occurred within the same paragraph as either "executive power" or "executive privilege." ${ }^{10}$ Obviously, such a search is potentially under and over inclusive. ${ }^{11}$ Any number of alternative search specifications might be used, ${ }^{12}$ but we saw no inherent bias in these parameters. This search produced cases that did not concern Executive power and we eliminated these cases from our data. ${ }^{13}$ The first author classified each opinion as favoring, or opposing, the asserted Executive power: Usually this aspect of opinions was extremely clear though, in a small number of cases, there were multiple holdings in an opinion and some considered legal judgment was necessary. ${ }^{14}$ Our final data consist of 201 distinct cases heard by 136 distinct judges. A list of all cases turned up by the research librarians appears in this online supplement: This includes our classification of the opinion in each case as either favoring the Executive, opposing the Executive, or not relevant to Executive power or privilege, often with very brief comments.

Schlanger et al. (2009) argue that District judges' written opinions are a minority of what District judges do and so omit much of the actual effects District judges have through the various actions they take: They recommend a more detailed analysis of District judges' dockets as preferred research

\footnotetext{
${ }^{9}$ Appendix A describes closely related data sets that are available but nevertheless do not meet our requirements, as well as a suitable data set that no longer seems to be available.

${ }^{10}$ We asked the librarians to record their exact search specification: This appears in Appendix B.

${ }^{11}$ Ironically, these search parameters did not produce Judge Paul Friedman's opinion in Campbell v. Clinton, $52 \mathrm{~F}$. Supp. 2d 34 (1999), aff'd 203 F.3d 19 (2000), cert. denied, 531 US 815 (2000), where the first author (with twentyfive other Members of Congress) sought a declaratory judgment that President Clinton's bombing Yugoslavia without the approval of Congress was not lawful. (We proceed anyway, taking this as an unanticipated gift for the appearance of objectivity of our research.) Judge Friedman ruled that the plaintiffs lacked standing, as Members of Congress, to sue for declaratory relief that the President had violated the War Powers Act and U.S. Constitution.

12 For example, Ducat and Dudley (1989, pp. 103 - 105) use a more complex definition of a case involving Presidential authority.

${ }^{13}$ For example, Simon v. Republic of Hungary, 37 F. Supp. 3d 381 (2014) where, in a case seeking restitution by holocaust survivors against Hungary, Judge Howell used an analogy to the American President's Executive power to conclude Executive agreements.

${ }^{14}$ The Dellums v. Bush case we referred to in our introduction is a good example. Judge Greene held that Members of Congress had standing to challenge President George H.W. Bush over the first Gulf war, but also held their challenge was not yet ripe. The first author scored the decision as opposing Presidential power, since the first holding (standing) gave Congress the power to challenge action by the President in matters of war in the future; while ripeness, the basis for the dismissal, might or might not be present in any future challenge.
} 
practice on the behavior of District judges and, in general, we concur. Yet Schlanger et al. (p. 88) note that things are quite different for Circuit judges: “...ultimately, those judges issue some kind of written decision... in the vast majority of federal appellate cases that are adjudicated..." Therefore, we think the tenor of District judges' written opinions are particularly telling for our hypothesis-perhaps more so than outcomes of cases-since writing opinions is a central task of Circuit judges. Written opinions of District judges resemble auditions for Circuit duties, and may be the most relevant evidence a President's judicial advisors have about District judges' potential behavior as Circuit judges.

Rowland and Carp (1996, pp. 18-21) point out that relying on published opinions (judges themselves decide whether to publish each opinion) suffers from potential self-selection issues. At the time of their writing, this was perhaps a powerful general concern. The advent of electronically collected Federal District Court opinions through Westlaw and Lexis has somewhat mitigated that potential bias (Schlanger et al. 2009, p. 102) by encouraging judges to submit more opinions; but it is still true that District judges ultimately decide which opinions they will provide to a publisher such as Westlaw. ${ }^{15}$ However, when Presidents and their advisors screen a District judge candidate for a Circuit appointment, screening procedures will include a request for all opinions of that District judge. ${ }^{16}$ Therefore, we believe District judges cannot effectively misrepresent the whole body of their opinions through selective publication from that body: Such misrepresentation will be discovered during screening for a Circuit appointment. Therefore we are comfortable with our focus on published opinions of District judges: Given the institutional details of the elevation process, and the nature of work on the Circuit bench, we believe (1) published opinions will be representative of the whole body of each District judge's interesting ${ }^{17}$ written opinions, and (2) the Executive will regard District judge's written opinions as a useful message concerning their likely behavior as a Circuit judge.

\footnotetext{
${ }^{15}$ Source: Personal communications between librarians at the Fowler School of Law and a Westlaw representative. ${ }^{16}$ The first author served on the Judiciary Committee of the US House of Representatives and also as the Executive Assistant to the Deputy Attorney General of the United States when the Reagan Administration was making its first judicial appointments. In both positions, he learned of the practices of the Department of Justice in reviewing candidates for federal judgeships. We were not able to find any published source for the proposition cited; but the first author offers his own experience that this practice is, indeed, followed. Indeed, it is implausible in the extreme that a President or Department of Justice would allow a candidate for a circuit judgeship to send only some of his or her opinions to the Department for evaluation. The fact that an opinion is not published does not mean that it does not exist: the judge and the parties keep copies.

${ }^{17}$ Many opinions of District judges will be ministerial, dealing with motions in the process of trying a case, short of decisions that dispose of a case on the merits. These kinds of decisions are often not published.
} 


\section{Independent Variables}

\subsection{Age and the age-specific cumulative future hazard for elevation}

The Federal Judicial Center maintains the remarkable "Biographical Directory of Article III Federal Judges, 1789-present" (hereafter the "Biographical Directory") containing extensive information on all U.S. Article III Federal judges, including background and exact dates of birth, nomination, confirmation, elevation or reassignment to other courts, passage into senior status, ${ }^{18}$ termination from the courts, and death. ${ }^{19}$ From these data, we calculate our central independent variable $A_{i j}$, the exact age in decimal years ${ }^{20}$ of judge $j$ when she issued opinion $i j$. We also take two characteristics of each judge (gender and ethnicity) from the Biographical Directory and include indicators for female judges $\left(\right.$ Female $\left._{j}=1\right)$ and non-white judges (Nonwhite No $=1$ ) in some model specifications. We also used the Biographical Directory to compute $H(A)$, the age-specific cumulative future hazard for elevation to the Circuit (the grey graph of Figure 1; the population is the one described in Figure 1's notes). ${ }^{21}$ Because the Biographical Directory contains the entire population of Federal Article III judges, the $H(A)$ we compute from it is not an estimate: Therefore, when we later use $H(A)$ as an explanatory variable in several regression models there is no reason to correct the standard error of a parameter estimate on $H(A)$.

\subsection{Probability of elevation due to current vacancies}

Vacancies on Circuit Courts play a key supporting role in our analysis-allowing us to choose between competing interpretations of our central finding. Savchak et al. (2006) find that when vacancies

\footnotetext{
${ }^{18}$ At a minimum age of 65, Federal judges may enter senior status, a reduced workload short of full retirement.

${ }^{19}$ www.fjc.gov/history/nome.nsf/page/judges.html. While birth year is included, exact birth dates are withheld for living judges (for privacy reasons). Using various resources (e.g. Senate confirmation transcripts and legal databases), our research librarians found exact birth dates for all but two of the living judges (we set those two judges' birth dates to July 2 nd of their birth year).

${ }^{20}$ We take the difference in days between the exact date of the opinion and the judge's exact birth date and divide this difference by 365.25 to compute "exact age in decimal years."

${ }^{21}$ In all calculations involving elevation to Circuit status, we exclude statutory elevations due to Acts of Congress (e.g. the creation of the Federal Circuit in 1982, elevating existing judges on the U. S. Court of Claims and the U.S. Court of Customs and Patent Appeals to Circuit status). Within the population of all District judges who were living and non-retired during our study period (January 1st, 1960 to December 31st, 2015), there are judges whose first confirmation as a District judge occurred as far back as 1918; so for the purpose of computing $H(A)$, we used the population of all District judges first confirmed that far back. As part of our sensitivity analysis, we calculated $H(A)$ using a more restricted population of judges - those first confirmed, or still living and non-retired, between 1960 and 2015 (this is 2,213 judges). Using this alternative calculation of $H(A)$ has no notable effect on our results.
} 
appear, elevation probabilities for specific judges depend on three distinct vacancy types. First, there are "new-seat vacancies" created by Acts of Congress: We take the dates when these appear, the circuits they appear in, and the dates they vanish (when filled) from a history of these Acts maintained by the Federal Courts ${ }^{22}$ and the Biographical Directory.

One of two types of vacancies will also appear as Circuit judges exit from active service, ${ }^{23}$ depending on the perspective of each District judge within that circuit. Each Circuit Court seat is associated with a state within that Circuit. ${ }^{24}$ For instance Judge Susan Graber occupies an "Oregon seat" on the Ninth Circuit Court of Appeals, and is currently old enough (and has served long enough) either to retire or to take senior status: If she were to do either one, an "Oregon seat" on the Ninth Circuit Court would become vacant. From the perspective of a District of Oregon District judge, this is a "same-state vacancy:" This is our second type of vacancy. However, from the perspective of District judges on all other District courts within the Ninth Circuit (that is, all except for District of Oregon judges), one calls that an "other-state vacancy:" This is our third type of vacancy.

Savchak et al. (2006) show that a given District judge's elevation probability at any given time depends quite strongly on which of these three types of vacancies has appeared: In order of decreasing elevation probability, the ranking is same-state vacancies, then new-seat vacancies, and finally otherstate vacancies. Following much of Savchak et alia's explanations and findings, we convert the three vacancy types into probabilities of elevation created by each type of vacancy, sum them (and demean the sum) to create the variable $P E V_{i j}$, the "probability of elevation from current vacancies." Appendix $C$ details the construction of this variable.

\subsection{Politics: Presidents, the judges they nominated, and the Senate}

When a Republican (Democratic) President nominated judge $j$ to the District court, we let $J_{j}=R(D)$ and we refer to judges $j$ for whom $J_{j}=R$ or $D$ as "Republican judges" or "Democratic judges" though, in fact, we do not know the party identification (if any) of those judges. Similarly, we let $P_{i j}=R(D)$ if, at the time of opinion $i j$, a Republican (Democrat) occupied the Presidency. The two

\footnotetext{
${ }^{22}$ http://www.uscourts.gov/judges-judgeships/authorized-judgeships/chronological-history-authorizedjudgeships-courts-appeals.

${ }^{23}$ They do this by taking senior status and/or full retirement, by an early resignation, by reassignment or elevation, or by death while in active service. When judges take senior status, they free an authorized judgeship position (Burbank, Plager and Ablavsky 2012).

${ }^{24}$ We take data on this seat-state association from Wikipedia pages on each Circuit court; for instance, for the Ninth Circuit this is https://en.wikipedia.org/wiki/United States Court of Appeals for the Ninth Circuit under the heading "Succession of seats."
} 
variables $J_{j}$ and $P_{i j}$ then generate four group indicators $Q_{i j}^{a b}=\mathbf{1}\left(J_{j}=a \cap P_{i j}=b\right)$ : For instance, $Q_{i j}^{D R}=1$ if judge $j$ is Democratic and, at the time of opinion $i j$, the President was a Republican.

Senate control may also be important to District judges aspiring to elevation for at least two very different reasons. First and obviously, the Senate must confirm a President's Article III judicial nominations. Second and less obviously, suppose a District judge must rule on a statutory case and she faces a President with relatively strong Senate support: In such an instance she might think 'Why anger this President when my ruling may well be undone by legislative means?' Therefore, we also compute a simple index of the current President's power in the Senate at the time of opinion $i j$. Let $N_{i j}^{R}, N_{i j}^{D}$ and $N_{i j}^{O}$ denote total numbers ${ }^{25}$ of Republican, Democratic, and Other (third party or independent) senators sitting at the time of opinion $i j$; then $P S P_{i j}=\left[2 \cdot \mathbf{1}\left(P_{i j}=R\right)-1\right] \cdot\left(N_{i j}^{R}-N_{i j}^{D}\right) /\left(N_{i j}^{R}+N_{i j}^{D}+N_{i j}^{O}\right)$ is our measure of Presidential power in the Senate, with group-specific versions $P S P_{i j}^{a b}=Q_{i j}^{a b} \cdot P S P_{i j}$.

With the four group indicators $Q_{i j}^{a b}$ and the four group-specific Senate power variables $P S P_{i j}^{a b}$, a potential model with no intercept could have up to eight "politics parameters" or seven with an intercept. ${ }^{26}$ With just 201 observations, including all of these is profligate with degrees of freedom. Yet we always see joint significance of these politics variables at five percent or better when we include all seven of them and, most importantly, including all seven invariably generates the weakest evidence favoring our chief hypothesis (in comparison to including reduced dimension versions of these political variables, which are generally not jointly significant either). Given the institutional realities of Senate confirmation of Presidential nominations, the influence of political factors could well be interactively complex. For all these reasons, wherever we enter our political variables in multivariate analyses, we always enter a complete seven-variable vector. We use a specific formulation of the seven politics variables to make interpretation of their estimated effects relatively straightforward:

1. $R \_J u d g e_{j}$ : This is $Q_{i j}^{R R}+Q_{i j}^{R D}$ or $\mathbf{1}\left(J_{j}=R\right)$, an indicator for Republican judges, demeaned across all observations. This variable's parameter estimate then represents the difference between the favorable opinion propensity (the change in the latent index) of Republican and Democratic judges,

\footnotetext{
${ }^{25}$ The U. S. Senate maintains these data at https://www.senate.gov/history/partydiv.htm. When third party or independent senators had declared that they caucus with either major party, we included them in the total senators of that major party rather than the "Other" total.

${ }^{26}$ Parameterized and put differently, a model with an intercept could include $J_{j}, P_{i j}$, and $P S P_{i j}$; their three twoway interactions; and their single three-way interaction.
} 
while the estimated model's intercept represents the mean favorable opinion propensity across all judges in the sample.

2 and 3. $R_{-}$Partisan $_{i j}$ and $D_{-}$Partisan $_{i j}$ : These are, respectively, $Q_{i j}^{R R}$ demeaned across all observations for which $J_{j}=R$ (zero otherwise), and $Q_{i j}^{D D}$ demeaned across all observations for which $J_{j}=D$ (zero otherwise). ${ }^{27}$ These variables' parameter estimates represent the change in a judge's favorable opinion propensity between sitting own-party Presidents and sitting other-party presidents: Positive estimates indicate "pure partisanship" ${ }^{28}$ of Republican $\left(R_{-}\right.$Partisan $\left._{i j}\right)$ or Democratic $\left(D \_\right.$Partisan $\left._{i j}\right)$ judges.

4, 5, 6, and 7. Sen_Power ${ }_{i j}^{a b}$ : These are $P S P_{i j}^{a b}$ demeaned across all observations for which $Q_{i j}^{a b}=1$ (zero otherwise). These four variables' parameter estimates represent the change in a judge's favorable opinion propensity due to the sitting President's power in the Senate, conditional on the $a b$ combination (the party of the judge and the party of the President).

\subsection{The topic of the case}

Some specifications also include three indicators for topically similar cases. In our sample, we have twelve cases related to the Nixon Administration's troubles with the "Watergate" scandal. Perhaps these cases differed from others in some essential respect or had correlated rulings, so we include an

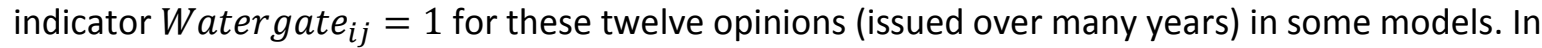
terms of raw numbers of cases (thirty of them), 1988 was far and away the most active year in our sample: This was the year of challenges to the constitutionality of the U.S. Sentencing Commission Guidelines. We also include an indicator $\operatorname{Sent}_{-} \operatorname{Com}_{i j}=1$ for the twenty-four such cases in our sample (all of them occurred in 1988) in some models. Finally, Ducat and Dudley (1989) first documented that in our kinds of cases (challenges to Executive authority), District judge opinions favor Executive authority

\footnotetext{
${ }^{27}$ Our phrasing " $Z_{i j}$ : This is $X_{i j}$ demeaned across all observations for which [set of $i j$ defined by a condition] (zero otherwise)" is shorthand for the following: Compute the conditional mean $\bar{X}_{s e t}$ of the $X_{i j}$ such that $i j \in$ set; then demean those same observations using that conditional mean, i.e. compute $Z_{i j}=X_{i j}-\bar{X}_{s e t}$ for the $i j \in$ set; and finally let $Z_{i j}=0$ for all the $i j \notin s e t$.

${ }^{28}$ What we call pure partisanship might be another person's good reasoning in the face of the opposing party's routine mistakes. Our label is for a simple reference term which can be applied symmetrically.
} 
more strongly in cases involving "Foreign or Military Affairs" more than they do in "Domestic" cases. ${ }^{29}$ Therefore, we sometimes include the indicator Foreign ${ }_{i j}=1$, coded as Ducat and Dudley coded their own indicator variable.

5. Data Analysis and Results

\subsection{District judge support for the Executive declines with judge age: Four demonstrations}

The indicator $y_{i j}$ codes each written opinion $i$ of judge $j$ as favoring Executive authority $\left(y_{i j}=1\right)$ or opposing it $\left(y_{i j}=0\right)$ ). Let $r_{i j}$ indicate the rank of each opinion $i j$ by ascending age $A_{i j}$ (with $r_{i j}=1$ being the youngest). ${ }^{30}$ To get an initial sense of the basic data series, and to set up some later statistical analysis, define sequences of " $w$-opinion moving averages" of exact age in decimal years and favorable opinion proportions $\left(\bar{A}_{\tau}^{w}, \bar{y}_{\tau}^{w}\right)$ as follows (here $w$ stands for the "window" of these moving averages):

$$
\bar{A}_{\tau}^{w}=\sum_{r_{i j}=\tau}^{\tau+w-1} A_{i j} / w \text { and } \bar{y}_{\tau}^{w}=\sum_{r_{i j}=\tau}^{\tau+w-1} y_{i j} / w, \text { for } \tau=1,2, \ldots, 202-w
$$

We graph such pairs (joining adjacent points $\tau$ and $\tau+1$ with lines) using a moving average window $w=40$; this is the heavy black line in Figure 2 (we return to the dashed gray lines later). The figure strongly suggests that the probability of favorable opinions mostly declines with judge age. At its second value, the sequence reaches its maximum $\bar{y}_{2}^{40}=0.675$ at an average age $\bar{A}_{2}^{40}=50.3$ years. Beginning around an average age of 57 years, however, a steep decline in favorable opinion proportions begins and reaches a nadir $\bar{y}_{133}^{40}=0.300$ at an average age $\bar{A}_{133}^{40}=66.4$ years. At greater ages, support for Executive power appears to recover a bit, but this is not a statistically significant turnaround.

While visually striking, Figure 2 is not formal statistical inference: For that we turn to a bootstrap (Efron and Tibshirani 1993) of moving average variability under the null hypothesis that the $y_{i j}$ are independently and identically distributed Bernoulli draws. The moving averages $\bar{y}_{\tau}^{w}$ are simple filters:

\footnotetext{
${ }^{29}$ Ducat and Dudley (1989, p. 109) describe their indicator variable thusly: "The dummy variable 'Foreign/Military Affairs' was coded 1 if the case involved an issue of presidential control over foreign relations or military affairs, including presidential war-making powers. Domestic cases were coded as $0 . "$ We followed this description to the best of our ability in coding our own indicator.

${ }^{30}$ There are two tied pairs of $A_{i j}$ values, but for one of those pairs the opinion was the same-so for the purpose of our moving average analysis below it will be inconsequential which is ranked higher. We randomly broke the second tie to induce a full and strong ranking of the 201 opinions by exact age of judge at the time of the opinion.
} 
Figure 2: Moving Averages of Favorable Opinions and Judge Age, and Estimates from a Logistic Regression of Opinions on a Natural Cubic Spline of Judge Age.

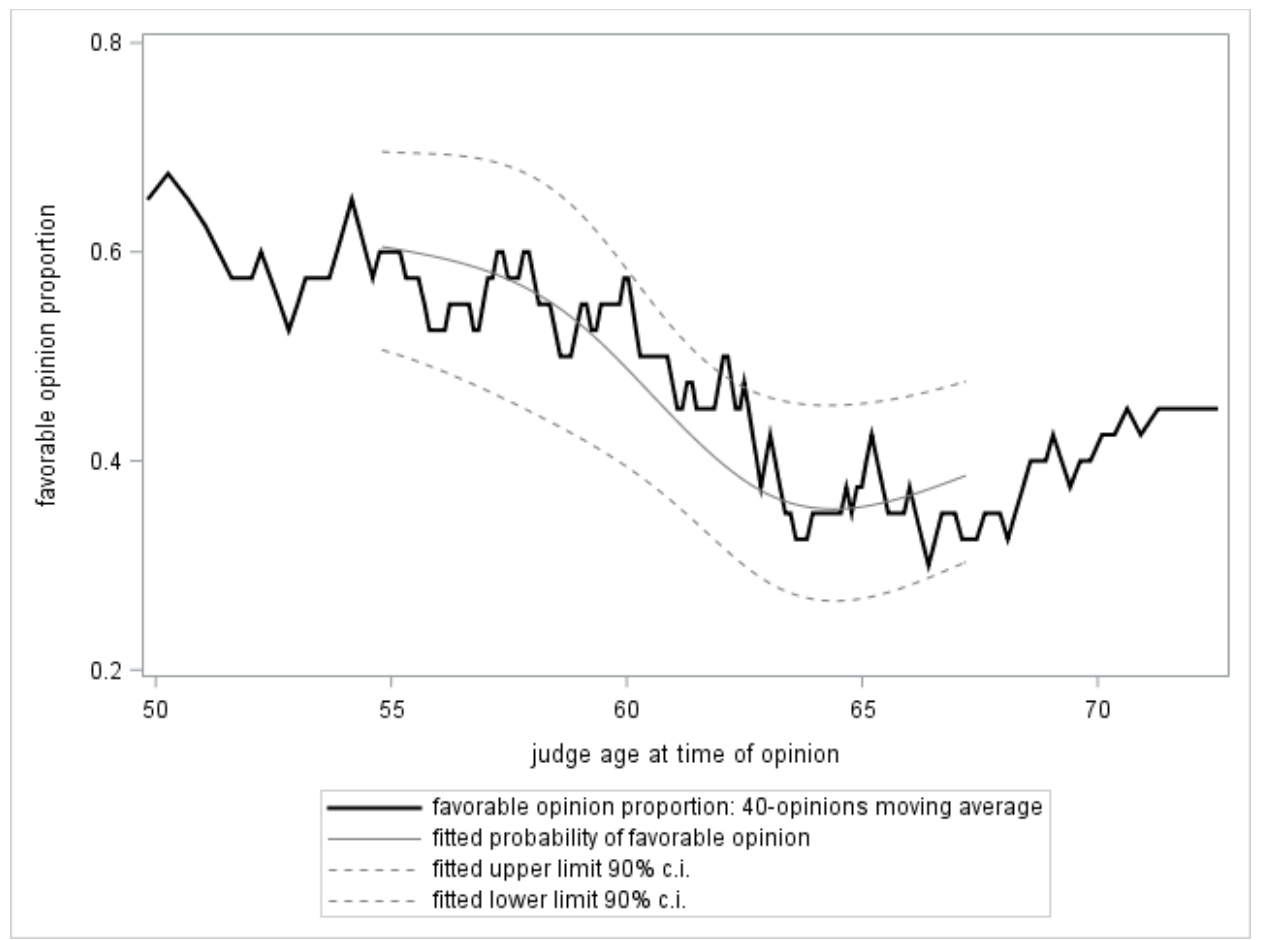

Figure 3: Moving Averages of Favorable Opinions and Judge Age, and Estimates from a Logistic Regression of Opinions on the Hazard for Elevation to the Courts of Appeals at Each Judge Age.

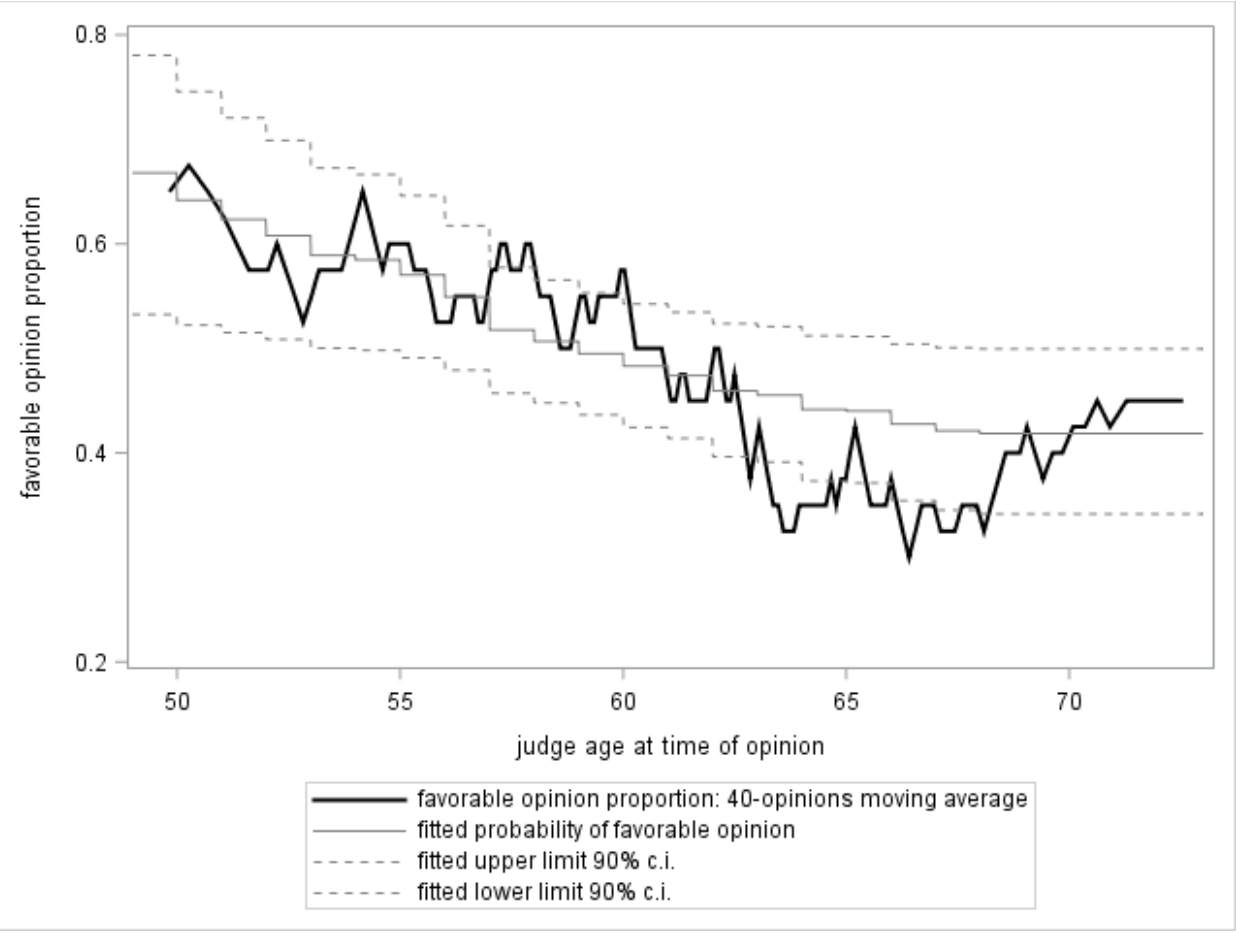


Low (versus high) $w$ values give high (versus low) frequency filters. Our hypothesis is either a gradual decline in favorable opinion probabilities (with marked heterogeneity of judges' preferences or beliefs) or a single discontinuous fall in favorable opinion probabilities (with little or no judge heterogeneity): In either case we expect that sample variability of lower frequency (higher $w$ ) filter values will be larger than what one could reasonably expect from an i.i.d. Bernoulli sequence.

In our sample, the $y_{i j}$ are a set of 101 ones and 100 zeroes: We resample this set with replacement to create 10,000 new sequences of 201 observations. We then apply the moving average filters to each of these sequences, creating a derived sequence of $202-w$ filter values $\bar{y}_{\tau}^{w}$, and record statistics of variability in each derived sequence (the range, maximum - minimum; the interquartile range, 75th centile -25 th centile; the 90 th centile -10 th centile; and the 95 th centile -5 th centile). We then examine the distribution of these variability statistics across the 10,000 sequences and record the 95th centile of each distribution, for each $w$ considered: These are $\alpha=0.05$ critical values against the null hypothesis that our sample is composed of i.i.d. Bernoulli draws. We just calculate the same statistics of variability over the sample values of $\bar{y}_{\tau}^{w}$ and compare these to the bootstrapped critical values.

Table 1 shows results from this procedure. Higher frequency filtering (that is, values of $w \leq 40$ ) of the opinions $y_{i j}$ do not (statistically speaking) reveal excessive variability relative to an i.i.d. Bernoulli

Table 1: Sample Values and Bootstrapped Critical Values of Variability Statistics of Moving Averages of the Opinions Indicators $y_{i j}$, Using Various Moving Average Windows $w$.

\begin{tabular}{|c|c|c|c|c|c|c|}
\hline \multirow{2}{*}{$\begin{array}{c}\text { variability } \\
\text { statistic }\end{array}$} & \multicolumn{2}{|c|}{$w=10$} & \multicolumn{2}{|c|}{$w=20$} & \multicolumn{2}{|c|}{$w=40$} \\
\hline & $\begin{array}{c}\text { sample } \\
\text { value }\end{array}$ & $\begin{array}{c}\text { critical } \\
\text { value }\end{array}$ & $\begin{array}{c}\text { sample } \\
\text { value }\end{array}$ & $\begin{array}{l}\text { critical } \\
\text { value }\end{array}$ & $\begin{array}{c}\text { sample } \\
\text { value }\end{array}$ & $\begin{array}{c}\text { critical } \\
\text { value }\end{array}$ \\
\hline$c_{75}-c_{25}$ & 0.200 & 0.300 & 0.200 & 0.200 & 0.150 & 0.175 \\
\hline$c_{90}-c_{10}$ & 0.400 & 0.500 & 0.250 & 0.350 & 0.250 & 0.275 \\
\hline$c_{95}-c_{05}$ & 0.500 & 0.600 & 0.350 & 0.450 & 0.275 & 0.325 \\
\hline \multirow[t]{3}{*}{$\max -\min$} & 0.700 & 0.900 & 0.450 & 0.600 & 0.375 & 0.400 \\
\hline & \multicolumn{2}{|c|}{$w=60$} & \multicolumn{2}{|c|}{$w=80$} & \multicolumn{2}{|c|}{$w=100$} \\
\hline & $\begin{array}{c}\text { sample } \\
\text { value }\end{array}$ & $\begin{array}{l}\text { critical } \\
\text { value }\end{array}$ & $\begin{array}{c}\text { sample } \\
\text { value }\end{array}$ & $\begin{array}{l}\text { critical } \\
\text { value }\end{array}$ & $\begin{array}{l}\text { sample } \\
\text { value }\end{array}$ & $\begin{array}{c}\text { critical } \\
\text { value }\end{array}$ \\
\hline$c_{75}-c_{25}$ & 0.167 & 0.150 & 0.137 & 0.113 & 0.110 & 0.090 \\
\hline$c_{90}-c_{10}$ & 0.217 & 0.217 & 0.200 & 0.175 & 0.160 & 0.130 \\
\hline$c_{95}-c_{05}$ & 0.250 & 0.250 & 0.212 & 0.188 & 0.170 & 0.150 \\
\hline $\max -\min$ & 0.283 & 0.283 & 0.237 & 0.225 & 0.200 & 0.170 \\
\hline
\end{tabular}

Notes: $c_{n}$ denotes the $n$th centile of values in a sequence of moving averages. The bootstrapped $\alpha=0.05$ critical values are against the one-sided null hypothesis that opinions follow an i.i.d. Bernoulli process: Sample values above those critical values reject that null. 
process. Though visually striking, even the $w=40$ filter values displayed in Figure 2 do not produce statistically significant evidence against an i.i.d. Bernoulli process. It is precisely lower frequency filterings (values of $w \geq 60$ ) that produce uniform and statistically significant evidence against the hypothesis that opinions are an i.i.d. Bernoulli process-as we expect under our hypothesis.

Figure 2 also displays results from a logistic regression analysis of the opinions and their relationship to the age of District judges. Generally speaking one might model $\operatorname{Pr}\left(y_{i j}=1 \mid A_{i j}\right)$ using a discrete choice model (such as the logistic model we use) conditioned on some flexible function of $A_{i j}$. For a flexible function of $A_{i j}$, capturing what appears to be a gradual and perhaps smoothly changing likelihood of a favorable opinion, we turn to Hastie, Tibshirani and Friedman's (2009, pp. 141-146) presentation of the natural cubic spline function.

The observed support of our chief independent variable $A_{i j}$ is $[37.5,85.3]$ : Place a sequence of knots $\xi_{k}, k=0,1,2, \ldots K, K+1$, on this interval so that $37.5=\xi_{0}<\xi_{1}<\xi_{2}<\cdots \xi_{K}<\xi_{K+1}=85.3$, letting $\xi$ denote the vector of knots. A cubic spline is a sequence of cubic functions, each lying on an interval between adjacent knots $\xi_{k}$ and $\xi_{k+1}$, which have been constrained to be equal (and to have equal first and second derivatives) at shared knots: Put differently, the cubic functions on the intervals are "knotted together" so that the entire cubic spline function has $C^{2}$ continuity across intervals. Typically, one places the interior knots $\xi_{1}<\xi_{2}<\cdots \xi_{K}$ to split the observed support of the independent variable into equally-sized intervals: We use $K=4$ interior knots placed at the 20th, 40th, 60th and 80th centiles of the sample distribution of $A_{i j} \cdot{ }^{31}$

A natural cubic spline further restricts the functions on the boundary intervals $\left[\xi_{0}, \xi_{1}\right]$ and $\left[\xi_{K}, \xi_{K+1}\right]$ to be linear functions instead of cubic functions. Sampling variability of cubic splines is particularly great on boundary intervals, so some recommend replacing the cubic functions there with linear functions to conserve degrees of freedom and additionally warn against paying much attention to their estimates (Hastie, Tibshirani and Friedman 2009, pp. 144-145), so we omit estimated linear boundary interval functions from Figure 2. Natural cubic splines have several desirable mathematical and statistical properties: They are quite flexible while they consume just $K-1$ degrees of freedom ${ }^{32}$ above and beyond the regression intercept. The use of well-chosen basis functions, embodying all the knots and constraints, greatly simplifies the estimation of natural cubic splines: We use the basis

\footnotetext{
${ }^{31}$ Of knot vectors creating equally-sized interior intervals, $K=4$ was selected by the Aikake Information Criterion.

${ }^{32}$ While there are $K-1$ cubic functions using $4(K-1)$ parameters in all, and two linear functions using 4 parameters in all, there are three constraints (equality, and equal first and second derivatives) on parameters operating at every interior knot (giving back $3 K$ parameters). So we have $4(K-1)+4-3 K=K$ parameters in all-one of which is the regression intercept.
} 
functions described by Hastie, Tibshirani and Friedman (2009, pp. 144-146). We let $S\left(A_{i j} \mid \xi, \theta\right)$ denote the natural cubic spline without its constant basis function, where the vector $\theta$ denotes the $K-1$ (nonintercept) parameters multiplying the $K-1$ (non-constant) basis functions of the natural cubic spline. ${ }^{33}$

In Figure 2, the solid gray line is predicted probabilities of a favorable opinion at our maximum likelihood estimates $\hat{I}$ and $\hat{\theta}$ of the parameters in this logistic probability model of opinions $y_{i j}$ (with no regressors other than the intercept and natural cubic spline of judge age at the time of an opinion):

$$
\operatorname{Pr}\left(y_{i j}=1 \mid A_{i j}\right)=\Lambda\left[I+S\left(A_{i j} \mid \xi, \theta\right)\right], \text { where } \Lambda[x]=\left(1+e^{-x}\right)^{-1} .
$$

The pair of short-dashed gray lines are a 90\% confidence region around these predicted probabilities. Testing the null hypothesis $\theta=0$ is another way (more parametric than Table 1 , but still quite flexible) of testing the null hypothesis that the $y_{i j}$ are i.i.d. Bernoulli draws: The Wald statistic against this null is $\chi_{3}^{2}=8.79$ with a $\mathrm{p}$-value $p=0.032$, a moderate rejection which agrees with the bootstrapping analysis of low-frequency variability in Table 1.

The natural cubic spline of age (or any other flexible function of age) is, from our perspective, a proxy for elevation opportunities of District judges at each age. Another approach to our central hypothesis is to place the cumulative future hazard for elevation $H\left(A_{i j}\right)$ on the right-hand-side of our models of opinions instead of some flexible function of ages $A_{i j}$. That is, we might instead estimate $I$ and the scalar coefficient $\gamma$ in the model

$$
\operatorname{Pr}\left(y_{i j}=1 \mid A_{i j}\right)=\Lambda\left[I+\gamma \cdot H\left(A_{i j}\right)\right]
$$

Figure 3 shows results of this estimation in the same manner Figure 2 showed the estimated natural cubic spline. The solid gray line is again predicted probabilities of a favorable opinion at each age, at our maximum likelihood estimates $\hat{I}$ and $\hat{\gamma}$ in the eq. 3 model of opinions $y_{i j}$ (with no regressors other than the intercept and the hazard for elevation at each age), and the short-dash gray lines are a $90 \%$ confidence region around these predicted probabilities. Rejection of $\gamma=0$ (in favor of $\gamma>0$ ) supports

\footnotetext{
${ }^{33} \mathrm{~A}$ constant function and its parameter (intercept) is one of the basis functions of any spline. We include an intercept as a separate term in our regressions, so in our notation $S\left(A_{i j} \mid \xi, \theta\right)$ is only composed of the $K-1$ nonconstant basis functions and, in particular, the vector $\theta$ does not include the intercept. In terms of our $K=4$, with a corresponding parameter vector $\theta=\left(\theta_{2}, \theta_{3}, \theta_{4}\right)$, our $S\left(A_{i j} \mid \xi, \theta\right)$ is $\theta_{2} A_{i j}+\theta_{3} N_{3}\left(A_{i j} \mid \xi\right)+\theta_{4} N_{4}\left(A_{i j} \mid \xi\right)$ where the basis functions $N_{k}\left(A_{i j} \mid \xi\right)$ are exactly as defined by Hastie, Tibshirani and Friedman (2009, pp. 145-146, eqs. 5.4 and 5.5).
} 
our hypothesis that a judge's opinion will tend to favor the Executive when the judge has a relatively high hazard for elevation to the Circuit. In fact $\hat{\gamma}=8.30$ with an estimated standard error 3.64: The Wald statistic against the null is $\chi_{1}^{2}=5.08$ with a two-tailed $p$-value $p=0.023$, a moderate rejection. ${ }^{34}$

In general we might think of each judge $j$ as having some critical age $A_{j}^{c}$, depending on that judge's own valuation of Circuit court elevation, her outside opportunities, her beliefs concerning Executive behavior, and so forth, at which judge $j$ ceases favoring the Executive for the instrumental reason of elevation to the Circuit court. Substantial heterogeneity of judges' critical ages $A_{j}^{c}$ would imply that the probability of favorable opinions is a smoothly changing function of age in the population. The two preceding analyses (based on natural cubic splines and the cumulative future hazard for elevation $H(A)$, respectively) both assumed this case of substantial heterogeneity of judges.

It is possible, however, that there is little underlying heterogeneity of judges: In this instance it might be better to characterize all judges by a single common critical age $A^{c}$. This suggests a discontinuous step function model of the age effect (if any) with two intercepts: $I_{y}$ for "young" judges with $A_{j} \leq A^{c}$, and $I_{o}$ for "old" judges with $A_{j}>A^{c}$. Obviously this latter model requires estimation of the unknown intercept shift $\Delta=I_{y}-I_{o}$; but the unknown "change point" $A^{c}$ must also be estimated. The logit model is:

$$
\operatorname{Pr}\left(y_{i j}=1 \mid A_{i j}\right)=\Lambda\left[I_{o}+\Delta \cdot \mathbf{1}\left(A_{i j} \leq A^{c}\right)\right]
$$

Davies (1977), Hawkins (1987) and Andrews (1993) describe a technique to carry out this estimation and, in particular, to perform statistical inference when a parameter (our change point $A^{c}$ ) is not identified under the null hypothesis (which is $\Delta=0$ ). Andrews explains that some a priori restrictions on the allowable range of change points must be adopted: We set the minimum allowable $A^{c}$ to 55 years (in deference to Gerald Ford's stated preference in our opening sentence) and the maximum allowable $A^{c}$ to 65 years (the age at which retirement or senior status first become options for judges). Within this range we find that $\widehat{A^{c}}=61.385$ years and $\widehat{\Delta}=0.787$ maximize the log likelihood and, employing Andrews' inference technique along with Estrella's (2003) updated statistical tables, we find a $p$-value $p \in(0.05,0.10)$ against the hypothesis that $\Delta=0 .{ }^{35}$ Figure 4 shows the results of this estimation.

\footnotetext{
${ }^{34}$ To repeat, $H(A)$ is a calculation from the population data of the Biographical Directory, not an estimate from a sample drawn from that population. Because of this, correction of the standard error of $\hat{\gamma}$ is not called for.

${ }^{35}$ Casting matters in Andrews' (1993, pp. 839-841) notation, a fraction $\pi_{1}=0.209$ of our 201 judges have ages strictly below 55 years, and a fraction $\pi_{2}=0.7015$ of our judges have ages with supremum 65 years. A parameter $\lambda=\pi_{2}\left(1-\pi_{1}\right) /\left[\pi_{1}\left(1-\pi_{2}\right)\right]$ indexes Andrews' and Estrella's (2003) statistical tables. Our $\lambda$ is thus 8.89 so we
} 
Figure 4: Moving Averages of Favorable Opinions and Judge Age, and Estimates from a Logistic Regression of Opinions on an Intercept and Indicator for Judge Age Less Than 61.385 Years.

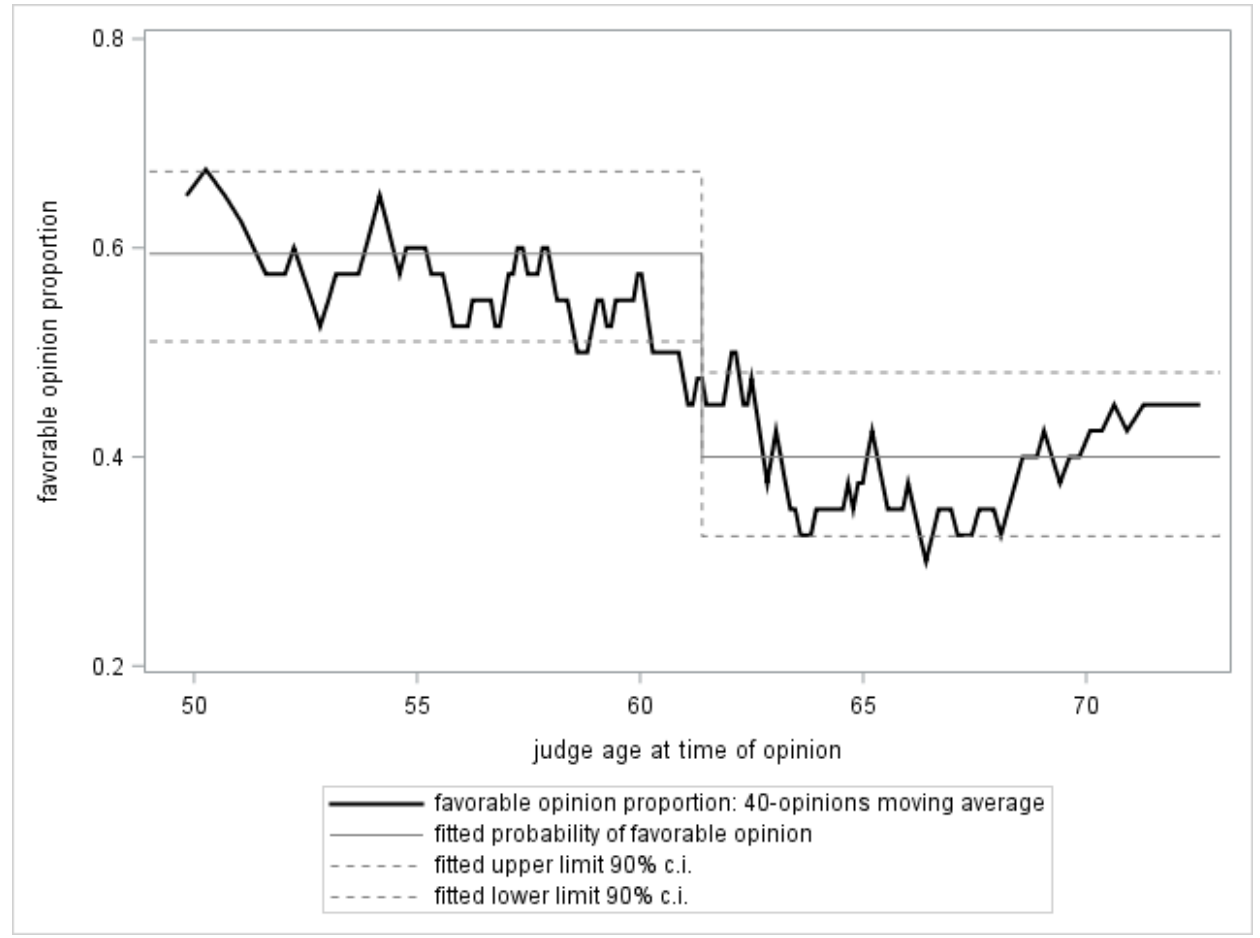

This change point model will be useful in other analyses below. However, we simply use it as an alternative specification and do not wish to push a literal interpretation of it (e.g. that all District judges immediately lower their support for the executive at 61.385 years of age) for several reasons. First, age 61 seems a rather late age for this change since the hazard for elevation has already fallen to 0.028 by age 61: Indeed, more searching data analysis suggests that an earlier change point in the neighborhood of age 55 is also a possibility. Second, and more generally, it is difficult to choose between the step function model of eq. (4) and the smoothly changing models of eqs. (2) and (3). ${ }^{36}$

All four of our analyses in this section support our primary finding: In cases involving Executive power or privilege, younger District judges are significantly more likely to favor the Executive than older District judges. The effect is an appreciable one as well. In Figure 4, estimated probabilities of favoring the Executive are 0.5943 for the "young" judges with $A_{j} \leq 61.385$ and 0.3999 for the "old" judges with $A_{j}>61.385$. In about one of every five cases, younger judges rule differently than older judges.

use the $\lambda=9.00$ row in Estella's tables, yielding critical values of 6.50 (at ten percent) and 8.04 (at five percent) for the LR statistic. Our computed value of this LR statistic is 7.63, falling between those two critical values. ${ }^{36}$ We elaborate on both points in our online supplement. 


\subsection{Multivariate analysis}

We now report results from multivariate analyses of the opinions $y_{i j}$. This serves three purposes. First, we check whether our primary result in the previous section survives when other relevant regressors have their chance to explain variance of opinion too. In particular, we add other demographic variables (gender and ethnicity indicators for the judges), the seven political variables discussed in Section 4.3, and the case-topic variables discussed in section 4.4. Second, we check whether our estimates are consistent with well-known results of other scholars who worked with data sets like our own. Finally, we have interest in the relationship (if any) between vacancies on the Circuit Courts and the opinions of our District judges. As discussed in Section 4.2 and elaborated in Appendix C, we have constructed a regressor $P E V_{i j}$ which is the probability of elevation due to vacancies on the Circuit Courts (any and all vacancies that are conventionally open to judge $j$ at the time of her opinion $i$ ).

Our first set of multivariate specifications add some or all of these regressors to the simple model based on the cumulative future hazard for elevation $H\left(A_{i j}\right)$ (the eq. 3 model): Table 2 reports the estimation results from those specifications. Our second set of multivariate specifications add some or all of the regressors to the simple model based on an age change point (the eq. 4 model): Table 3 reports the estimation results from those specifications. ${ }^{37}$ We display these results as average estimated marginal effects of changes in regressors (rather than coefficient estimates) for easy interpretation ${ }^{38}$, along with estimated standard errors and $p$-values of the average estimated marginal effects. ${ }^{39}$

\footnotetext{
${ }^{37}$ Specifications based on the natural cubic spline (the eq. 2 model) produce very similar results quantitatively, though joint significance of the three spline basis functions is lost in four of eight specifications (across the eight specifications, the maximum and minimum p-values are 0.15 and 0.044 ). We think this occurs because of the greater burden of degrees of freedom associated with estimating the natural cubic spline.

${ }^{38}$ For the continuous regressors (the first four and last four regressors in Tables 2 and 3), the size of the change in the regressor needs to appear so that the average marginal effect can be interpreted most clearly: This appears in the left-most column for the first four continuous regressors, and in a table note for the last four continuous regressors. For all regressors which are binary indicators (unity or zero), the change is from unity to zero.

${ }^{39}$ For 30 of the 136 distinct judges in our data set, we have repeated observations of opinions accounting for an appreciable 96 of the 201 opinions. Because of this, we use a robust covariance matrix estimator clustered on judges $j$ (Morel, Bokossa and Neerchal 2003; SAS Institute Inc. 2015, p. 3353-4) to calculate standard errors and pvalues of estimated average marginal effects. We also explored adding random effects for judges. We found that in the specifications reported in Tables 2 and 3, the estimated variance of random effects is almost always zero (in all but one specification). The degree of repetition within judges may be too unevenly distributed over too few judges for a meaningful random effects variance estimate. However, we also carried out a sensitivity analysis, imposing a progressively greater random effects variance $\sigma^{2}$ on the specification (1) in Table 2. At $\sigma^{2}=4$, twice the log likelihood of the model has dropped more than 15 points and the $p$-value testing whether the coefficient on $H\left(A_{i j}\right)$ is zero has risen to just $p=0.049$. This suggests that empirically implausible amounts of unobserved judge heterogeneity would have to be imposed to overturn results favoring our chief hypothesis.
} 
The first row (of both tables) speaks clearly to our first purpose. The probability that District judges favor the Executive (statistically) significantly increases with the hazard for elevation (and so declines with age) for all specifications in Table 2, and young judges (aged less than 61.385 years) are significantly more likely to favor the Executive for all specifications in Table 3. Moreover, the estimated average marginal effects show that the estimated size of the effect is highly robust to the particular specification: In about one of every five cases, younger judges appear to rule differently than older judges.

In most respects our other results resemble those of scholars who worked with similar data sets. We easily replicate Ducat and Dudley's (1989) statistically significant finding that District judges are more likely to favor the Executive in cases involving foreign policy and military matters (see the eighth row of both Tables 2 and 3). Our estimates are also consistent with previous findings that District judges were more likely to favor the Executive in the 1988 cases involving the U.S. Sentencing Commission Guidelines (Cohen 1991; Sisk, Heise, and Morriss 1998), though these estimates fail to reach statistical significance (see the ninth row of both Tables 2 and 3). Similarly our estimates are mostly consistent with a common finding (e.g. Rowland and Carp 1996) that partisanship helps to explain opinions of District judges: Our point estimates of "pure partisanship" indicate that our judges are somewhat more likely to favor an Executive of the same party as the Executive that nominated them, though again this fails to reach statistical significance (see the twelfth and thirteenth row of both Tables 2 and 3). ${ }^{40}$

The results also speak to our third purpose. According to the estimates in the third row of both tables, District judges in the eleven state Circuits are more likely to favor the Executive when the number and kinds of vacancies on their Circuit courts enhance their chances for elevation. The estimated effect is usually significant at the $\alpha=0.10$ level, but the effect size is smaller than that for the cumulative future hazard for elevation reported in the first rows of the table. This does not surprise us:

\footnotetext{
${ }^{40}$ However, the seven politics regressors are always highly statistically significant as a group. Largely this is because of a strong effect of one set of political regressors. When Republican District judges face Presidents whose party has greater strength in the U.S. Senate, they are increasingly likely to issue opinions favoring the Executive-and this effect is robustly significant (see the last two rows of Tables 2 and 3). Intriguingly this is true regardless of the President's party. Perhaps this indicates that (in one specific sense) Republican judges tend to be realists: Why, they may ask themselves, should they anger the President when that President may simply undo their opposing opinion (if statutorily based) by legislative means? However, when Democratic District judges face Presidents whose party has greater strength in the U.S. Senate, they are somewhat less likely to issue opinions favoring the Executive-though this effect never reaches conventional significance levels (see the fourteenth and fifteenth rows of Tables 2 and 3). And again this is true regardless of the President's party. Perhaps this indicates that (in one specific sense) Democratic judges tend to be idealists: Their opinions do not significantly respond to the possibility that their opinion will be rendered moot by legislative means. We do not see how these two results can have a conventional explanation in terms of partisanship. In the case of the Republican judges, it may be a strategic consideration related to career considerations and therefore generally in line with our hypothesis here. However, the Democratic judges do not appear to be affected similarly by this same strategic consideration.
} 
Table 2. Average Marginal Effects from Logistic Regressions of Opinions $y_{i j}$ on Various Regressors and Hazard for Elevation (Generalizing Eq. 3).

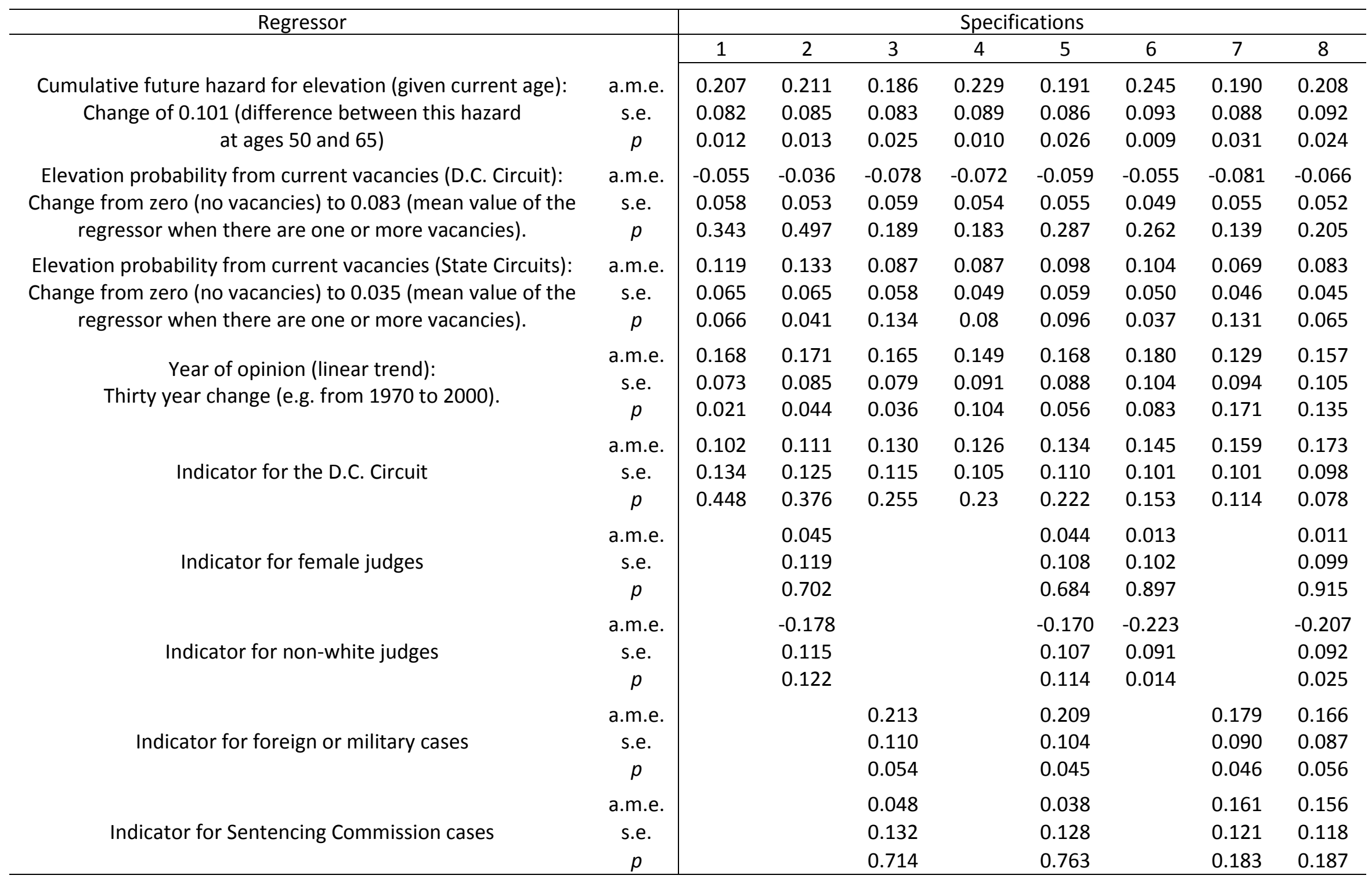


Table 2 (continued). Average Marginal Effects from Logistic Regressions of Opinions $y_{i j}$ on Various Regressors and Hazard for Elevation (Generalizing Eq. 3).

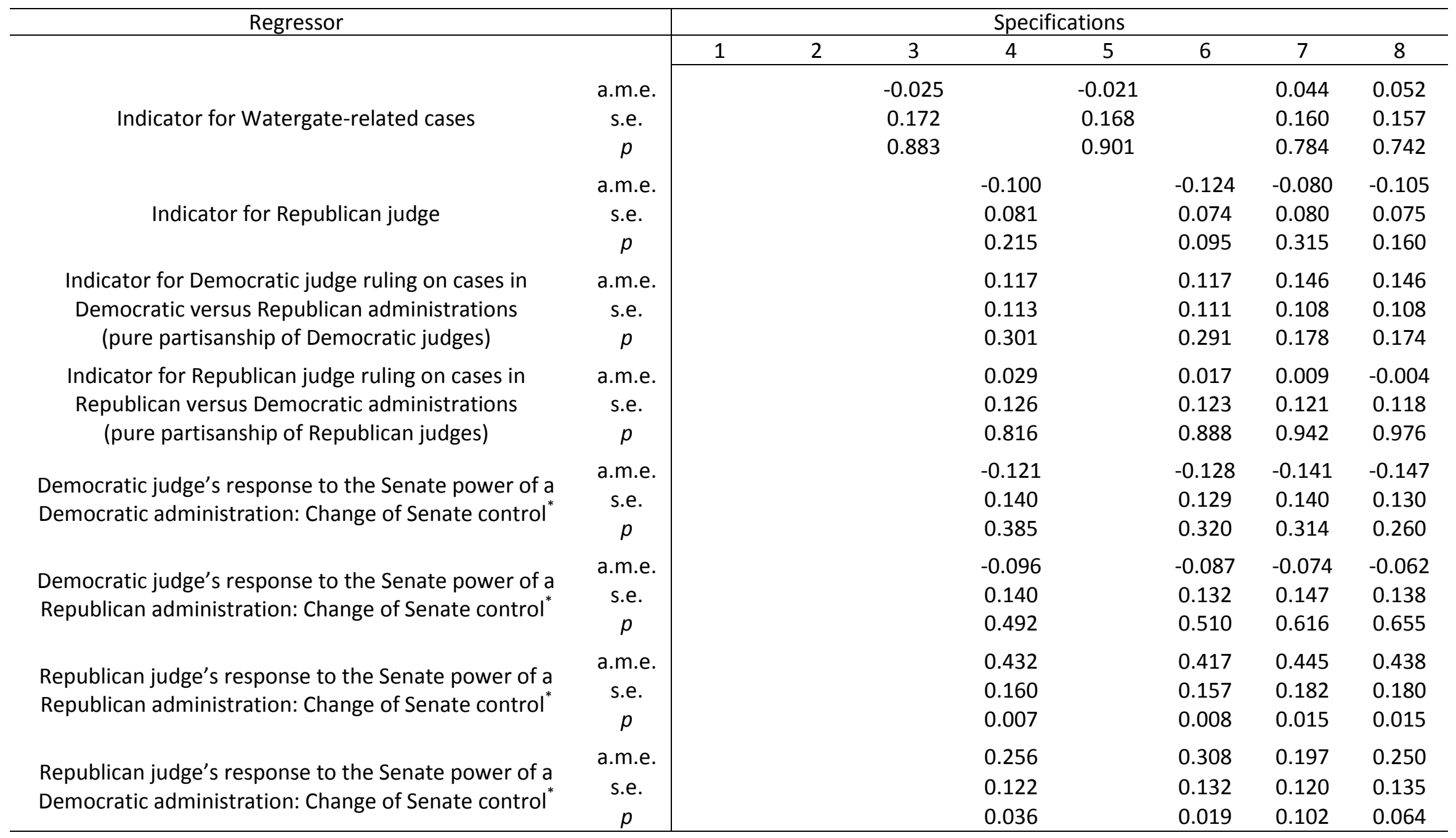

" Change of Senate control" means a change from the administration controlling $40 \%$ of Senate seats to $60 \%$ of Senate seats. 
Table 3. Average Marginal Effects from Logistic Regressions of Opinions $y_{i j}$ on Various Regressors and Younger Judges Indicator (Generalizing Eq. 4).

\begin{tabular}{|c|c|c|c|c|c|c|c|c|c|}
\hline \multicolumn{2}{|l|}{ Regressor } & \multicolumn{8}{|c|}{ Specifications } \\
\hline & & 1 & 2 & 3 & 4 & 5 & 6 & 7 & 8 \\
\hline $\begin{array}{l}\text { Age Change Point Effect: Indicator for age at opinion } \\
\text { less than or equal to } 61.385 \text { years }\end{array}$ & $\begin{array}{l}\text { a.m.e. } \\
\text { s.e. } \\
p\end{array}$ & $\begin{array}{l}0.194 \\
0.098 \\
0.047\end{array}$ & $\begin{array}{l}0.198 \\
0.087 \\
0.024\end{array}$ & $\begin{array}{l}0.187 \\
0.077 \\
0.016\end{array}$ & $\begin{array}{l}0.212 \\
0.066 \\
0.001\end{array}$ & $\begin{array}{l}0.193 \\
0.073 \\
0.008\end{array}$ & $\begin{array}{l}0.222 \\
0.062 \\
0.000\end{array}$ & $\begin{array}{l}0.191 \\
0.063 \\
0.002\end{array}$ & $\begin{array}{l}0.202 \\
0.060 \\
0.001\end{array}$ \\
\hline $\begin{array}{l}\text { Elevation probability from current vacancies (D.C. Circuit): } \\
\text { Change from zero (no vacancies) to } 0.083 \text { (mean value of the } \\
\text { regressor when there are one or more vacancies) }\end{array}$ & $\begin{array}{l}\text { a.m.e. } \\
\text { s.e. } \\
p\end{array}$ & $\begin{array}{c}-0.069 \\
0.057 \\
0.230\end{array}$ & $\begin{array}{c}-0.048 \\
0.053 \\
0.363\end{array}$ & $\begin{array}{c}-0.091 \\
0.058 \\
0.118\end{array}$ & $\begin{array}{c}-0.079 \\
0.054 \\
0.143\end{array}$ & $\begin{array}{c}-0.070 \\
0.054 \\
0.198\end{array}$ & $\begin{array}{c}-0.060 \\
0.050 \\
0.232\end{array}$ & $\begin{array}{c}-0.089 \\
0.055 \\
0.104\end{array}$ & $\begin{array}{c}-0.071 \\
0.052 \\
0.171\end{array}$ \\
\hline $\begin{array}{l}\text { Year of opinion (linear trend): } \\
\text { Thirty year change (e.g. from } 1970 \text { to 2000) }\end{array}$ & $\begin{array}{c}\text { a.m.e. } \\
\text { s.e. } \\
p\end{array}$ & $\begin{array}{l}0.161 \\
0.074 \\
0.030\end{array}$ & $\begin{array}{l}0.157 \\
0.085 \\
0.065\end{array}$ & $\begin{array}{l}0.161 \\
0.081 \\
0.047\end{array}$ & $\begin{array}{l}0.139 \\
0.090 \\
0.123\end{array}$ & $\begin{array}{l}0.156 \\
0.090 \\
0.082\end{array}$ & $\begin{array}{l}0.159 \\
0.101 \\
0.115\end{array}$ & $\begin{array}{l}0.128 \\
0.092 \\
0.168\end{array}$ & $\begin{array}{l}0.146 \\
0.103 \\
0.158\end{array}$ \\
\hline Indicator for non-white judges & $\begin{array}{c}\text { a.m.e. } \\
\text { s.e. } \\
p\end{array}$ & & $\begin{array}{c}-0.178 \\
0.114 \\
0.120\end{array}$ & & & $\begin{array}{c}-0.171 \\
0.107 \\
0.110\end{array}$ & $\begin{array}{c}-0.218 \\
0.092 \\
0.017\end{array}$ & & $\begin{array}{c}-0.202 \\
0.093 \\
0.029\end{array}$ \\
\hline Indicator for foreign or military cases & $\begin{array}{c}\text { a.m.e. } \\
\text { s.e. } \\
p\end{array}$ & & & $\begin{array}{l}0.219 \\
0.107 \\
0.041\end{array}$ & & $\begin{array}{l}0.215 \\
0.101 \\
0.033\end{array}$ & & $\begin{array}{l}0.189 \\
0.089 \\
0.033\end{array}$ & $\begin{array}{l}0.179 \\
0.086 \\
0.039\end{array}$ \\
\hline Indicator for Sentencing Commission cases & $\begin{array}{c}\text { a.m.e. } \\
\text { s.e. } \\
p\end{array}$ & & & $\begin{array}{l}0.038 \\
0.128 \\
0.763\end{array}$ & & $\begin{array}{l}0.026 \\
0.123 \\
0.831\end{array}$ & & $\begin{array}{l}0.144 \\
0.119 \\
0.225\end{array}$ & $\begin{array}{l}0.136 \\
0.116 \\
0.243\end{array}$ \\
\hline
\end{tabular}


Table 3 (continued). Average Marginal Effects from Logistic Regressions of Opinions $y_{i j}$ on Various Regressors and Younger Judges Indicator (Generalizing Eq. 4).

\begin{tabular}{|c|c|c|c|c|c|c|c|c|c|}
\hline Regressor & & \multicolumn{8}{|c|}{ Specifications } \\
\hline \multirow[b]{2}{*}{ Indicator for Watergate-related cases } & & 1 & 2 & 3 & 4 & 5 & 6 & 7 & 8 \\
\hline & $\begin{array}{l}\text { a.m.e. } \\
\text { s.e. } \\
p\end{array}$ & & & $\begin{array}{l}-0.011 \\
0.173 \\
0.948\end{array}$ & & $\begin{array}{r}-0.004 \\
0.169 \\
0.983\end{array}$ & & $\begin{array}{l}0.047 \\
0.158 \\
0.767\end{array}$ & $\begin{array}{l}0.056 \\
0.156 \\
0.720\end{array}$ \\
\hline Indicator for Republican judge & $\begin{array}{l}\text { a.m.e. } \\
\text { s.e. } \\
p\end{array}$ & & & & $\begin{array}{l}-0.088 \\
0.082 \\
0.280\end{array}$ & & $\begin{array}{l}-0.106 \\
0.076 \\
0.163\end{array}$ & $\begin{array}{l}-0.073 \\
0.080 \\
0.361\end{array}$ & $\begin{array}{r}-0.091 \\
0.075 \\
0.226\end{array}$ \\
\hline $\begin{array}{l}\text { Indicator for Republican judge ruling on cases in } \\
\text { Republican versus Democratic administrations } \\
\text { (pure partisanship of Republican judges) }\end{array}$ & $\begin{array}{l}\text { a.m.e. } \\
\text { s.e. } \\
p\end{array}$ & & & & $\begin{array}{l}0.040 \\
0.126 \\
0.750\end{array}$ & & $\begin{array}{l}0.031 \\
0.123 \\
0.803\end{array}$ & $\begin{array}{l}0.022 \\
0.120 \\
0.855\end{array}$ & $\begin{array}{l}0.014 \\
0.119 \\
0.908\end{array}$ \\
\hline $\begin{array}{l}\text { Democratic judge's response to the Senate power of a } \\
\text { Democratic administration: Change of Senate control }\end{array}$ & $\begin{array}{c}\text { a.m.e. } \\
\text { s.e. } \\
p\end{array}$ & & & & $\begin{array}{c}-0.129 \\
0.136 \\
0.342\end{array}$ & & $\begin{array}{c}-0.136 \\
0.129 \\
0.292\end{array}$ & $\begin{array}{c}-0.145 \\
0.137 \\
0.289\end{array}$ & $\begin{array}{c}-0.150 \\
0.131 \\
0.251\end{array}$ \\
\hline $\begin{array}{l}\text { Republican judge's response to the Senate power of a } \\
\text { Republican administration: Change of Senate control }\end{array}$ & $\begin{array}{c}\text { a.m.e. } \\
\text { s.e. } \\
p\end{array}$ & & & & $\begin{array}{l}0.397 \\
0.154 \\
0.010\end{array}$ & & $\begin{array}{l}0.386 \\
0.153 \\
0.012\end{array}$ & $\begin{array}{l}0.398 \\
0.174 \\
0.023\end{array}$ & $\begin{array}{l}0.391 \\
0.174 \\
0.025\end{array}$ \\
\hline $\begin{array}{l}\text { Republican judge's response to the Senate power of a } \\
\text { Democratic administration: Change of Senate control }\end{array}$ & $\begin{array}{c}\text { a.m.e. } \\
\text { s.e. } \\
p\end{array}$ & & & & $\begin{array}{l}0.260 \\
0.122 \\
0.032\end{array}$ & & $\begin{array}{l}0.310 \\
0.133 \\
0.019\end{array}$ & $\begin{array}{l}0.201 \\
0.121 \\
0.097\end{array}$ & $\begin{array}{l}0.250 \\
0.137 \\
0.068\end{array}$ \\
\hline
\end{tabular}

" Change of Senate control" means a change from the administration controlling $40 \%$ of Senate seats to $60 \%$ of Senate seats. 
Much of the theoretical literature on dynamic optimization under uncertainty suggests that reactions to transient, contemporaneous resolutions of uncertainty (e.g. transient income shocks) will be smaller than reactions to changes in cumulative long run expectations (e.g. persistent wealth shocks).

However, the negative point estimates in the second row of both tables show that this is not so for District judges in the District of Columbia Circuit. Though none of these negative estimates reach any conventional level of significance, this contrast between the DC Circuit and the eleven state Circuits calls for comment. Note first that just one of the eleven currently active US Court of Appeals judges for the DC Circuit was a District judge in the District of Columbia, while forty-one of the one hundred and thirtyeight Court of Appeals judges in the eleven State Circuits were District judges within their Circuits (near thirty percent). ${ }^{41}$ Federal District judges in the District of Columbia, therefore, may not view themselves as candidates for elevation to the Circuit to the same extent as District judges in the State Circuits do.

A likely reason for the relatively low percentage of US District Judges for the District of Columbia being elevated to the US Court of Appeals for the District of Columbia Circuit is that there is no homestate Senator behind the appointment of a District judge in the District of Columbia. Accordingly, there is no home-state Senator to urge the promotion of a District judge to the DC Circuit Court. By contrast, the very process that led to a District judge's appointment (involving the support of a home-state Senator) would continue to the process of selecting a Circuit judge attributed to that state. Indeed, elevating a home-state District judge allows the home-state Senator to have influence in two appointments: the promotion to the Circuit, and appointment of a new District judge to the vacancy so created on the District court.

\subsection{Potential problems: Cohort effects, self-selection off courts, seniority and expected vacancies}

Obviously our judges' ages at the time of their opinions correlate somewhat with their birth year (Pearson correlation of $-0.47, p<0.0001$ ). Political psychologists have established that many political and social attitudes emerge from circumstances encountered during childhood, late adolescence and early adulthood, and many of those attitudes exhibit marked stability thereafter (Sears and Levy 2003). Judges who share the same birth year, or some limited range of birth years, may share distinct attitudes shaped by correlated circumstances during their shared times of maturation. Times change, so our main findings might reflect those changing times of maturation rather than judge age per se.

\footnotetext{
${ }^{41}$ Source: The Biographical Directory.
} 
To examine this possibility we partition the sequence of our judges' birth dates into sets

$g \in\{1,2, \ldots G\}$ of similar birth dates, with approximately equal numbers of opinions in them (keeping all opinions of any one judge in just one set $g$ ). This creates $G$ "generations" of our judges and their opinions. We then modify the age change point model of eq. (4) to include generation-specific fixed effects (or intercepts) $I_{o}^{g}$, yielding the model shown by eq. 5 :

$$
\operatorname{Pr}\left(y_{i j}=1 \mid A_{i j}\right)=\Lambda\left[I_{o}^{g}+\Delta \cdot \mathbf{1}\left(A_{i j} \leq A^{c}\right)\right]
$$

Using our previous estimate $\widehat{A^{c}}=61.385$, we may then use the fixed effects logit technique described by Breslow and Day (1980) and Chamberlain (1984) to condition out the fixed generation effects $I_{o}^{g}$ specific to each set $g$ of similar birth dates. In this way we can test the hypothesis that $\Delta=0$ (there is no difference between young and old judges in favoring the Executive) while controlling for cohort effects defined by each partition of judges into $G$ generations. We do this using the maximally expansive specification 8 from Table 3 -that is, including all of our covariates.

We repeat this exercise for $G=3,4,5,6$ and 12 distinct "generations" of judges and get quite stable results across these values of $G$. The parameter estimates $\widehat{\Delta}$ range from 0.78 to 0.89 with standard error estimates ranging from 0.37 to 0.42 and $p$-values (of Wald tests against the hypothesis $\Delta=0$ ) ranging from 0.028 to $0.036 .{ }^{42}$ We also formed an unequal partition of opinions into those from judges sharing the same birth year, resulting in 32 useful birth years containing an appreciably smaller useful sample size of 162 opinions. ${ }^{43}$ With this partition we estimate $\widehat{\Delta}=1.00$ with standard error 0.51 and $p$-value 0.051 . Given these results, we doubt that cohort effects can explain all of our age effect.

As District judges age, some leave the District Court bench before the time they would have first become eligible for partial retirement in senior status. Some are elevated to a Circuit Court; others resign to take other work; very small numbers are impeached and removed; similarly small numbers take senior status early due to disability; and of course some die. The minimum possible age of first eligibility for senior status has been 65 years throughout our sample period (Burbank, Plager and Ablavsky 2012) and, as shown earlier, the steep decline in the proportion of opinions favoring the

\footnotetext{
${ }^{42}$ Chamberlain (1984) points out that it's no longer possible to estimate average marginal effects (as we did in Tables 2 and 3) since the fixed effects have been conditioned out of the likelihood. This is why we cast this particular discussion in terms of estimates of the parameter $\Delta$ rather than estimates of average marginal effects. ${ }^{43}$ When partitioning into sets this small, there are inevitably some birth years in which opinions are all favorable, or all opposed, to the Executive: Since there is no variation in the dependent variable in those birth years, they provide no useful information when using this conditioning technique (Chamberlain 1984).
} 
Executive occurs almost entirely after age 56 and prior to age 65 . Any systematic difference between those judges who leave the bench during that age interval and those judges who stay could, in principle, explain our apparent age effect.

Using the Biographical Directory data for all judges confirmed from January 1st, 1918, to December 31st, 2015, our survival analysis indicates that a proportion 0.141 of judges serving on the District Court at age 56.5 had departed (for any of the reasons in the last paragraph) by age $64.5 .{ }^{44}$ From Tables 2 and 3, a fair common point estimate of our age effect is 0.2 (a one in five decline in opinions favoring the Executive). For argument's sake let us stipulate that selection is working against our hypothesis as strongly as possible. A pure selection hypothesis would maintain that the probabilities that departing, and remaining, judges support the Executive are both constant from age 56.5 to age 64.5, but are different from one another. Let $p_{d}$ and $p_{r}$ be these constant proportions of times that departing and remaining judges favored the Executive. Simple algebra implies that $0.141 \cdot\left(p_{d}-p_{r}\right)=0.2$, yielding $\left(p_{d}-p_{r}\right) \approx 1.42$ which is not possible for a difference between two probabilities. Suppose the departing judges had always favored the Executive $\left(p_{d}=1\right)$ while the remaining judges had favored the executive about $40 \%$ of the time ( $p_{r}=0.4$, as suggested by the lower step in Figure 4$)$. Then a pure selection hypothesis could explain at most $0.141 \cdot(1-0.40) \approx 0.085$, less than half our estimated age effect 0.2. These calculations cast serious doubt on the hypothesis that selection can explain all of our age effect. Empirically speaking, too few District Court judges leave the District court during this age interval to explain our estimated age effect.

So far we have controlled for neither the seniority of judges nor judges' expectations of future vacancies on their Circuit court. We follow Sisk, Heise and Morriss (1998) and define the seniority of a District judge as the decimal years since the Senate confirmed that judge's nomination to the District court. In our sample, the Pearson correlation between seniority and age is 0.74 and this seems to be substantial collinearity; but viewed differently, these two variables explain just $55 \%$ of the variance in one another. Therefore we can examine specifications that include both seniority and age. Cohen (1991) first introduced an interesting proxy measure for a District judge's expectation concerning future samestate vacancies ${ }^{45}$ (also employed by Sisk, Heise and Morriss). Within a District judge's circuit, there are

\footnotetext{
${ }^{44}$ As mentioned in footnote 19, the Biographical Directory excludes exact birth dates for living judges, so when using that population data (as opposed to our sample) to compute the survival function we can only approximate true birth dates to within half a year. Therefore we examine departure prior to age 64.5 rather than age 65.

${ }^{45}$ As far as we know, no one has attempted to control for District judge's expectations concerning the appearance of new-seat vacancies. (Given the reality of lags between first drafts of bills and their eventual implementation by Congress, surely such expectations emerge long before new Circuit seats actually appear.) Still, the results of Savchak et al. (2006) suggest that a District judge's probability of elevation when a same-state vacancy appears is
} 
almost always one or more active Circuit judges who occupy a seat associated with that District judge's state: The age of the oldest of those Circuit judges is a plausible proxy for increasing expectations of a same-state vacancy. We call this variable "vacancy expectation." We have added both seniority and vacancy expectation to the most expansive specification (specification 8) in Tables 2 and 3, and find no impact on any of our results. Neither variable produces anything near a statistically significant contribution to explained variance. In spite of its substantial collinearity with age, the addition of seniority hardly changes our estimates of age effects, nor does it change their statistical significance; and the same is true of the addition of vacancy expectation.

\section{Discussion and Conclusions}

There is a possibility that all judges, regardless of their vintage, politics, or any other factor we have considered here, experience some common cognitive change (between their mid-50s and mid-60s) that manifests as diminishing support for Executive power. Oliver Wendell Holmes (1899, p. 455) famously averred that "judges commonly are elderly men, and are more likely to hate at sight any analysis to which they are not accustomed, and which disturbs repose of mind, than to fall in love with novelties." Assuming Holmes' remark about elderly men isn't simply a gratuitous insult, one may infer that Holmes thought age brings a rigid cast of mind, mired in precedents, traditions and shopworn arguments. ${ }^{46}$ On the other hand Sisk, Heise and Morriss (1998, p. 1486-7) believed their results showed that "greater seniority tends to make a judge more worldly-wise (practical) and less taken with jurisprudential trends (nonoriginalist)" - very different from Holmes' view (if not quite opposite to it).

Whatever the true nature of any such change in cognition, a creative scholar may weave it into an explanation of our age effect. We appreciate that our main finding does not rule this out. However, we have a secondary finding, echoed by previous research (Cohen 1991, 1992; Sisk, Heise, and Morriss 1998; Epstein, Landes and Posner 2013), that District judges' decisions (opinions, sentences, and/or fines) react to promotion potential, in particular high-frequency arrivals and departures of various Circuit court vacancies, in ways that seem to gratify Executive preferences. We do not see how any plausible life-cycle theory of gradual changes in cognition can account for these reactions to a high-

four or five times larger than when a new-seat vacancy appears, and our own calculations show that this discrepancy is greatly magnified by the relative rareness of new-seat vacancies. So we think expectations of samestate vacancies will be quite dominant (assuming any expectations of future vacancies matter at all).

${ }^{46}$ Holmes was appointed to the Supreme Court at age 60 and served 30 years thereafter. His own judicial record, largely constructed in dissents, for which historians have called him "The Great Dissenter," strongly rebuts the generalization he made of other older men (see, e.g., Healy 2013). 
frequency phenomenon such as the arrival and departure of Circuit court vacancies. To the previous research, we add our new finding: Evidence that as they grow older, an appreciable number of District judges behave as if they exit a tournament or contest for the prize of elevation-for the perfectly understandable reason that they are eventually too old to be seriously considered for the prize.

Other things equal, personal advancement should not motivate Federal judges. It should not motivate elected officials either, but it is the judicial branch that the U.S. founders especially strove to make independent with life tenure and guarantee against diminution of compensation. We find that the hope for personal advancement cannot be excluded as an explanation of how Federal District judges decide cases particularly affecting the powers of the Executive. That is a great sadness. If this is true, then, for an individual harmed by excessive reach of Presidential power, the courts are not a completely reliable arbiter. The same is true for a Member of Congress trying to vindicate legislative responsibility against Executive encroachment. Not all grievances can be redressed by the political branches: only the courts can vindicate some rights, and it is distressing to have the scales biased. Further, bias, once practiced, is likely to be repeated; and bias, once accepted, is corrosive. A judge who will tip a decision in favor of her or his own advancement is a judge who will not decide on the merits in other contexts; and, as that perception becomes widespread, the judicial branch itself loses its only real authority: the respect of the people in a democratic republic.

Presidents could choose not to promote District judges to the Circuits. Klerman (1999, p. 456) noted that "Promotion was very uncommon in eighteenth-century England, and contemporaries regarded nonpromotion as a safeguard of judicial independence" though Klerman nevertheless believes that "an absolute policy against promotion is probably inadvisable." To be a Federal District judge is a tremendous honor. The vast majority of the decisions District judges make every day are never reviewed by any other court. The District judge is, thus, the final arbiter of justice in the vast majority of what she or he does. It is highly unlikely that our country would suffer a lack of top quality candidates for Federal District judge if the job carried with it the presumption of never serving on the Circuit. Some lawyers are expert litigators; their milieu should be the District Court. Others are excellent scholars; they belong on the Circuits. Some are both, and we understand the attractiveness of having as a judge reviewing trial court proceedings for error, someone who was herself or himself once a trial court judge. This study, however, has uncovered a cost that might offset that advantage-a cost measured in jeopardy to the most important aspect of a trial judge in our system, her or his neutrality, at least where suits involving the President are concerned. 
References

Baum, L., 2006, Judges and Their Audiences: A Perspective on Judicial Behavior. Princeton, NJ: Princeton Univ. Press.

Black, R. C. and R. J. Owens, 2016, Courting the president: How circuit court judges alter their behavior for promotion to the Supreme Court. American Journal of Political Science 60:30-43.

Breslow, N. E. and N. E. Day, 1980, Statistical Methods in Cancer Research, Volume 1: The analysis of case-control studies. Lyon, France: International Agency for Research on Cancer.

Burbank, S. B., S. J. Plager \& G. Ablavsky, 2012, Leaving the bench, 1970-2009: The choices Federal judges make, what influences those choices, and their consequences. University of Pennsylvania Law Review 161:1-102.

Campbell, T., 2004, Separation of Powers in Practice. Stanford, CA: Stanford Univ. Press.

Carp, R., K. Manning and R. Stidham, 2013, A first term assessment: The ideology of Barack Obama's district court appointees. Judicature 97:128-136.

Carp, R. and R. Stidham, 1998, The Federal Courts, 3rd Edition. Washington DC: Congressional Quarterly Press.

Chamberlain, G., 1984, Panel data. In Z. Griliches and M. D. Intrilligator, eds., Handbook of Econometrics, Volume II. Amsterdam, Netherlands: Elsevier.

Cohen, M., 1991, Explaining judicial behavior or what's 'unconstitutional' about the sentencing commission? Journal of Law, Economics and Organization 7:183-199.

Cohen, M., 1992, The motives of Judges: Empirical evidence from antitrust sentencing," 12 International Review of Law and Economics 12:13-30.

Cross, F., 2007, Decision Making in the U.S. Courts of Appeals. Stanford, CA: Stanford Univ. Press.

Davies, R. B., 1977, Hypothesis testing when a nuisance parameter Is present only under the alternative. Biometrika 64:247-254.

Ducat, C. R. and R. L. Dudley, 1989, Federal District judges and presidential power during the postwar era. Journal of Politics 51:98-118.

Gibbs, M., 1995, Incentive compensation in a corporate hierarchy. Journal of Accounting and Economics 19:247-277.

Epstein, L., W. Landes and R. Posner, 2013, The Behavior of Federal Judges. Cambridge, MA: Harvard Univ. Press. 
Estrella, A., 2003, Critical Values and $p$ Values of Bessel Process Distributions: Computation and Application to Structural Break Tests. Econometric Theory 19:1128-1143.

Halterman, H., J. Lobel, J. Starr, M. Ratner and J. Klimaski, 2001, The fog of war [powers]. Stanford Journal of International Law 37:197-204.

Hastie, T., R. Tibshirani and J. Friedman, 2009, The Elements of Statistical Learning, 2nd Edition. New York, NY: Springer.

Hawkins, D. L., 1987, A Test for a change point in a parametric model based on a maximal Wald-type statistic. Sankhya 49:368-376.

Healy, T., 2013, The Great Dissent: How Oliver Wendell Holmes Changed his Mind-and Changed the History of Free Speech in America. New York : Henry Holt and Company.

Holmes, O. W., 1899, Law in science and science in law. Harvard Law Review 12:443-463.

Johnson, S. W. and D. R. Songer, 2002, The influence of presidential versus home state senatorial preferences on the policy output of judges on the United States District Courts. Law and Society Review 36:657-676.

Klerman, D., 1999, Nonpromotion and judicial independence. Southern California Law Review 72:455463.

Kozinski, A., 2004, The real issues of judicial ethics. Hofstra Law Review 34:1095-1106.

Landes, W. and R. Posner, 2009, Rational judicial behavior. Journal of Legal Analysis 1:775-831.

Morel, J. G., M. C. Bokossa and N. K. Neerchal, 2003, Small sample correction for the variance of GEE estimators. Biometrical Journal 4:395-409.

Morriss, A. P., M. Heise and G. Sisk, 2005, Signaling and precedent in Federal District Court opinions. Supreme Court Economic Review 13: 63-97.

Posner, R. A., 1995, Overcoming Law. Cambridge, MA: Harvard Univ. Press.

Rosen, S., 1988, Promotions, elections and other contests. Journal of Institutional and Theoretical Economics 144:73-90.

Rotunda, R., 2015, Modern Constitutional Law, 11th ed. St. Paul, MN: West Academic Publishing.

Rowland, C. and R. Carp, 1996, Politics and Judgment in Federal District Courts. Lawrence, KS: University of Kansas Press.

Savchak, E., T. Hansford, D. Songer, K. Manning and R. Carp, 2006, Taking It to the next level: The elevation of District court judges to the U.S. Courts of Appeals. American Journal of Political Science 50:478-493. 


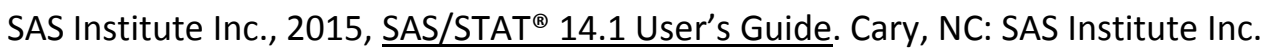

Schlanger, M., P. T. Kim, C. L. Boyd and A. D. Martin, 2009, How should we study District Judge decisionmaking? Washington University Journal of Law and Policy 29:83-112.

Sears, D. and S. Levy, 2003, Childhood and Adult Political Development. In L. Huddy, D. O. Sears and J. S. Levy, eds., Oxford Handbook of Political Psychology, 2nd Edition. Oxford, UK: Oxford Univ. Press.

Sisk, G. C. and M. Heise, 2012, Ideology 'all the way down'? An empirical study of establishment clause decisions in the Federal courts. Michigan Law Review 110:1201-1263.

Sisk, G. C., M. Heise and A. P. Morriss, 1998, Charting the influences on the judicial mind: An empirical study of judicial reasoning. 73 New York University Law Review 73:1377-1500.

2004, Searching for the soul of judicial decisionmaking: An empirical study of religious freedom decisions. Ohio State Law Journal 65:491-614.

Songer, D. R., 1998, United States Courts of Appeals Database Phase 1, 1925-1988. ICPSR02086-v1. Ann Arbor, MI: Inter-university Consortium for Political and Social Research [distributor]. https://doi.org/10.3886/ICPSR02086.v1

Spaeth, H. J., 1998, United States Supreme Court Judicial Database, 1953-1997 Terms. 9th ICPSR version. East Lansing, MI: Michigan State University, Dept. of Political Science [producer]. Ann Arbor, MI: Inter-university Consortium for Political and Social Research [distributor]. http://doi.org/10.3886/ICPSR09422.v9.

Sunstein, C., D. Schkade, L. M. Ellman and A. Sawicki, 2006, Are Judges Political? An Empirical Analysis of the Federal Judiciary. Washington, DC: Brookings Institution Press.

Swenson, K., 2006, Promotion of District Court judges to the US Courts of Appeals: Explaining President Reagan's promotions of his own appointees. Justice System Journal 27, 208-222.

Zorn, C., and J. Bowie, Ideological influences on decision making in the Federal judicial hierarchy: An empirical assessment. Journal of Politics 72, 1212-1221.

Zuk, G., D. J. Barrow, and G. S. Gryski, 2009, Multi-user database on the attributes of United States Appeals Court judges, 1801-2000. ICPSR06796-v2. Ann Arbor, MI: Inter-university Consortium for Political and Social Research [distributor]. http://doi.org/10.3886/ICPSR06796.v2 


\section{Appendix A: Related Studies and their Data Sets}

Like us, other researchers have assembled data sets of District judge opinions in specific kinds of cases. Sisk, Heise and Morriss (2004; see also Sisk and Heise 2012) assembled data on religious freedom cases. Epstein, Landes and Posner (2013) assembled several data sets of District judge opinions on specific issues not involving Executive power (opinions that generated Circuit opinions on appeal; opinions in Sentencing Commission cases; District judges' sentencing behavior itself; and District judges' decisions to dismiss claims under Rule 12(b)(6)). Ducat and Dudley (1989) also assembled a data set of District judge opinions in cases involving Presidential power (not Executive power more broadly construed; see Ducat and Dudley p. 104), but it seems this data set is no longer available.

There are important data sets of judicial opinions that nevertheless contain no opinions of District judges. Songer (1998; see also Zuk, Barrow and Gryski 2009) assembled a database of US Circuit Court opinions which has been relied upon in other research (e.g. Cross 2007, Landes and Posner 2009). Sunstein et al. (2006) also constructed a database of Circuit judge decisions which was later extended and used by Epstein, Landes and Posner (2013) as well.

Several data sets containing aspects of District judge opinions already exist. One class of data sets codes opinions, or judges themselves, for their apparent political ideology. Where a Supreme Court case originated from a District judge's decision, Spaeth's (1998) major database of Supreme Court decisions (also used by e.g. Swenson 2006; Zorn and Bowie 2010) includes information on that District opinion (but only for cases that eventually went up to the US Supreme Court) and records whether the opinion was liberal or conservative but, unfortunately, does not record whether the decision favored the Executive or not in relevant cases. The same is true of Rowland and Carp's (1996; see also Carp, Manning and Stidham 2013) extensive database of Federal District Court opinions and of additional data collected by Carp and Stidham (1998; see also Johnson and Songer 2002). 


\section{APPENDIX B: Case Search Procedure of our Librarians}

The two research librarians who assembled the initial set of published opinions for us wrote out the following account of their exact search procedure:

We ran the search in three different Westlaw content sets to confirm. Here are the details of these searches:

1. First, we pre-filtered to Cases $>$ All Federal Cases $>$ Federal District Courts and then entered your search string: advanced: (president /p "executive power" or "executive privilege") \& DA(aft 1231-1959 \& bef 12-31-2015). This yields 379 cases. From there, we filtered to reported [published] cases, which yields 315 .

2. Next, we used your search string in the main search bar, searching All State \& Federal Cases, and then post-filtering to Federal District. Ct. (381) and reported, of which there are 317.

Comparing this list to the one above, two cases erroneously appear twice: Tarros S.p.A. v. US (982 F. Supp. 2d) and In re Beck (526 F. Supp. 2d 1291).

3. Finally, we pre-filtered to Federal District Courts and used your search string in the main search bar. This yields 385 cases. From there, we filtered to reported cases, which yields 319 . Comparing this list to \#1 above, the four extra cases in this result set include: three from the U.S. Court of Military Commission Review (U.S. v. Hamdan, Khadr v. U.S. and U.S. v. Al Bahlul) and one from the Territorial Court of the Virgin Islands (Lettsome v. Waggoner, 1986 WL 1267671 (Terr.V.I.)). 


\section{APPENDIX C}

Construction of the Probability of Elevation from Current Vacancies

To begin, we define the following symbols and quantities.

$s$ indexes the states (and the District of Columbia) AK, AL, CA, ..., WY, and DC; and $s_{j}$ is the state of District Court judge $j$.

$t$ is time (date in days from a reference date); and $t(i j)$ is the time of judge $j$ 's opinion $i$.

$C$ indexes the circuits $1,2,3, \ldots, 11$, and DC; and $C_{t}(s)$ is the circuit of state $s$ at time $t$.

$N_{i j}^{d c}=$ the total number of District Court judges in judge $j^{\prime}$ s state at time $t(i j)$.

$V_{i j}^{\text {same }}=$ total "same-state vacancies" (given judge $j$ 's state) in judge $j$ 's circuit at time $t(i j)$.

$V_{i j}^{\text {new }}=$ total "new seat vacancies" in judge $j$ 's circuit at time $t(i j)$.

$V_{i j}^{\text {other }}=$ total "other-state vacancies" (given judge $j$ 's state) in judge $j$ 's circuit at time $t(i j)$.

$\rho(C)=$ the probability that a state in circuit $C$ retains a seat on its Circuit Court of Appeals when one of the state's own Circuit Court of Appeals judges leaves active service: put differently, the probability that any state in circuit $C$ retains its own same-state vacancy. This is calculated separately for each circuit from the Biographical Directory and especially the Wikipedia information on Circuit Court seat succession within each Circuit.

Then the probability that judge $j$ will fill one of $V_{i j}^{s a m e}$ same-state vacancies at time $t(i j)$ is

$$
P E V_{i j}^{\text {same }}=\rho\left[C_{t(i j)}\left(s_{j}\right)\right] V_{i j}^{\text {same }} / N_{i j}^{d c} .
$$

$h r_{t}(s)=$ the proportion (share) of U.S. House of Representatives members that state $s$ has, among all of the states in Circuit $C_{t}(s)$, at time $t$.

$|C|=$ the total number of states in Circuit $C$. Note that $\left|C_{t}(s)\right|^{-1}$ is then the proportion (share) of U.S. Senators that state $s$ has (among all of the states in its own Circuit) at time $t$.

$\pi_{t}(s)=\max \left(h r_{t}(s),\left|C_{t}(s)\right|^{-1}\right)$, maximum within-circuit U.S. legislative political power held by state $s$ at time $t$.

$\Pi_{t}(s)=\pi_{t}(s) /\left(\sum_{s^{\prime} \in C_{t}(s)} \pi_{t}\left(s^{\prime}\right)\right)$, the share of maximum within-circuit U.S. legislative political power held by state $s$, among all of the states in Circuit $C_{t}(s)$, at time $t$. We assume that $\Pi_{t}(s)$ is the probability that state $s$ gets a "new-seat vacancy" in its circuit. 
Then the probability that judge $j$ will fill one of $V_{i j}^{n e w}$ new-seat vacancies at time $t(i j)$ is

$$
P E V_{i j}^{\text {new }}=\Pi_{t(i j)}\left(s_{j}\right) V_{i j}^{\text {new }} / N_{i j}^{d c}
$$

$C_{t}^{c}(s)=$ states in $C_{t}(s)$ which do not have same-state vacancies at time $t$. These are states which are in competition with state $s$ to fill any other-state vacancies at time $t$, should those vacancies not be retained by their original "owners" (any other-state vacancy for state $s$ is definitionally a same-state vacancy for another state in the circuit of state $s$ ).

$\Pi_{t}^{c}(s)=\pi_{t}(s) /\left(\sum_{s^{\prime} \in C_{t}^{c}(s)} \pi_{t}\left(s^{\prime}\right)\right)$, the share of maximum within-circuit Federal legislative political power held by state $s$, among all of the states in $C_{t}^{c}(s)$, at time $t$. We assume that $\Pi_{t}^{c}(s)$ is the probability that state $s$ gets an "other-seat vacancy" in its circuit when that vacancy is not retained by its original "owner."

Then the probability that judge $j$ will fill one of $V_{i j}^{\text {other }}$ other-state vacancies at time $t(i j)$ is

$$
P E V_{i j}^{\text {other }}=\Pi_{t(i j)}^{c}\left(s_{j}\right)\left(1-\rho\left[C_{t(i j)}\left(s_{j}\right)\right]\right) V_{i j}^{\text {other }} / N_{i j}^{d c} .
$$

The regressor "Elevation probability from current vacancies (State Circuits)" mentioned in Section 4.2, and referenced in Tables 2 and 3, is then the sum of the three probabilities defined above,

$$
P E V_{i j}=P E V_{i j}^{\text {same }}+P E V_{i j}^{n e w}+P E V_{i j}^{\text {other }} .
$$

In the sample, correlations between the vacancy counts $V_{i j}^{n e w}, V_{i j}^{s a m e}$, and $V_{i j}^{\text {other }}$ are small and insignificant, so we treat covariances among them as zero in constructing this regressor. 